\title{
Structural, Optical and Photocatalytic Activity of The Cerium Doped Ba2TiMo06 Double Perovskite.
}

\section{Taher Ghrib ( $\nabla$ ghribt@gmail.com )}

Imam Abdulrahman Bin Faisal University https://orcid.org/0000-0003-3750-9460

\section{Athaa Al-Otaibi}

Imam Abdulrahman Bin Faisal University

\section{Qasim Mahmoud}

Imam Abdulrahman Bin Faisal University

\section{Filiz Ercan}

Imam Abdulrahman Bin Faisal University

\section{Asghar Ali}

Federal University of Uberlândia

\section{Abdullah A. Manda}

Imam Abdulrahman Bin Faisal University

\section{Research Article}

Keywords: Ba2TiMo06, Double perovskite, Methyl Blue (MO) dye, Photodegradation

Posted Date: May 25th, 2021

DOl: https://doi.org/10.21203/rs.3.rs-548214/v1

License: (c) (i) This work is licensed under a Creative Commons Attribution 4.0 International License.

Read Full License 


\title{
Structural, optical and photocatalytic activity
}

\section{of the Cerium doped $\mathrm{Ba}_{2} \mathrm{TiMoO}_{6}$ double perovskite.}

Taher Ghrib ${ }^{\mathrm{a}, \mathrm{b},{ }^{*}}$, Athaa Al-Otaibi ${ }^{\mathrm{a}, \mathrm{b}}$, Qasim Mahmoud ${ }^{\mathrm{a}, \mathrm{b}}$, Filiz Ercan ${ }^{\mathrm{a}, \mathrm{b}}$, Asghar Alic, Abdullah A. Manda $^{\mathrm{d}}$

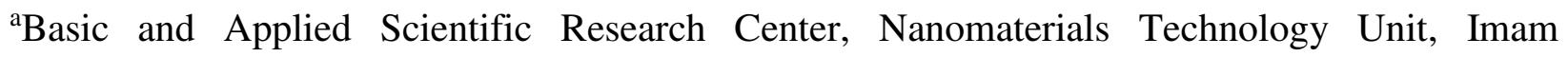
Abdulrahman Bin Faisal University, P.O. Box 1982, 31441, Dammam, Saudi Arabia

${ }^{\mathrm{b}}$ Department of physics, College of Science, Imam Abdulrahman Bin Faisal University, P.O. Box 1982, 31441, City Dammam, Saudi Arabia

${ }^{c}$ Laboratory of Photochemistry and Materials Science, Institute of Chemistry, Federal University of Uberlândia, Brazil

${ }^{\mathrm{d}}$ College of Engineering, , Imam Abdulrahman Bin Faisal University, 31451, Dammam, Saudi Arabia

\begin{abstract}
:
In this work, it was highlighted synthesis strategy and fundamental characterization of the pure and $\mathrm{Ce}$ doped $\mathrm{Ba}_{2} \mathrm{TiMoO}_{6}$ with different $\mathrm{Ce}$ concentrations were presented. It was investigated its thermal stability by using the Thermal Gravimetric Analysis and Differential Thermal Analysis. The crystal structures and the purity of the compounds were analyzed by X-ray diffraction (XRD) and Fourier transform infrared (FTIR) spectroscopy. The Surface morphology was examined by using Scanning Electron Microscopy (SEM), Transmission Electron Microscopy (TEM) and surface area analysis. The optical properties were examined by using the UV-Vis diffuse reflectance and photoluminescence (PL) spectroscopies. The prepared $\mathrm{Ba}_{2} \mathrm{TiMoO}_{6}$ nanopowders are characterized by band gap of $3.41 \sim 3.6 \mathrm{eV}$ and violet emission of $426.67 \mathrm{~nm}$ wavelength. The degradation efficiency was found approximately $16 \%$ of Methyl Blue (MO) after 120 min duration. Our results will predicate new Perovskites materials, which can be used for future environmental applications.
\end{abstract}

Keywords: $\mathrm{Ba}_{2} \mathrm{TiMoO}_{6}$, Double perovskite, Methyl Blue (MO) dye, Photodegradation

* Corresponding Author: thghrib@iau.edu.sa 


\section{Introduction}

The main cause of environmental pollution are cosmetics, pesticides, pharmaceuticals, personal and household care products, and toxic heavy elements. These synthetic chemicals have a broadly used and are essential for the modern erea [1, 2]. Among different pollutants, Synthetic dyes are played a key role in environmental pollutants, with an adverse effect direct or indirect on human and aquatic life [3, 4]. Among different pollutants, Synthetic dyes are played a key role in environmental pollutants, with an adverse effect direct or indirect on human and aquatic life. Synthetic Dyes mainly concern with water pollution, as colored effluents are released from industries sectors (textile, leather, and pharmaceutical). Dye-polluted water can mix into the food cycle of living creatures to cause phenotypic and genotypic disorders in humans, plants, and animals [5, 6]. According to a recent survey, more than a hundred types of organic dyes are available in the market, with an annual production of $7 \times 10^{5}$ tons. Among the different dyes, besides these dyes, Methyl Blue (MB)Dyes are frequently used in the different industrial sectors[7]. The utilization of MB-contaminated water is the main cause of different human diseases, such as diarrhea, jaundice, agitation, tachycardia, vomiting, and paralysis, etc.[8]. Due to these negative impacts, the removal of dyes from contaminated water has received more consideration. For this purpose, different strategies and techniques have been Examined to eradicate dyes (e.g., electron oxidation, ozonation, electro-kinetic coagulation with ions, membrane filtration, and microbial degradation)[9-13]. Among these techniques, photocatalytic degradation has been widely used for contaminated water treatments due to its eco-friendly nature and low cost[14, 15]. Numerous catalyst have been investigated for dye degradation such as TMDSc-graphene, polyethylene-TiO 2 , Hollow cobalt NPs,Si/Six core shell nanowires, Sns nano particles, silver nanoparticles etc.[16-20]. However, these compounds have some disadvantages e.g., limiting by its UV activation, or complexity in synthesis process, however these compounds have some disadvantages e.g., limiting by its UV activation, or complexity in the synthesis process, consequently new compounds (i.e., Perovskites materials) recently developed to overcome these difficulties, and widely used for environmental pollution. Perovskites materials constitute the main family of crystalline oxides described for the first time in 1830 by the geologist Gustav Rose who named it in honor of a great Russian mineralogist, Count Lev Aleksevich von Perovski. It is made of alkaline earth cation (A) and transition cation (B) and oxide anions constituting material of 
chemical formula $\mathrm{ABO}_{3}$ [21]. The perovskite double oxides known since 1960s of chemical formula $\mathrm{A}_{2} \mathrm{BB}^{\prime} \mathrm{O}_{6}$ [22], Its unit cell consists of two merged perovskite oxide $\mathrm{ABO}_{3}$ and has a variety of crystalline structures at room temperature, e. g. cubic $(\mathrm{Fm} \overline{3} \mathrm{~m})$ as the $\mathrm{Ba}_{2} \mathrm{FeMoO}_{6}[23$, 24], monoclinic $\left(\mathrm{P} 2_{1} / \mathrm{n}\right)$ as the $\mathrm{Ca}_{2} \mathrm{FeMoO}_{6}[24,25]$, and tetragonal (I4/m) as the $\mathrm{Sr}_{2} \mathrm{CoWO}_{6}$ [26]. Several methods were used to synthesize Perovskite materials, i.e. Zhang et al used the hydrothermal method to synthesize the $\mathrm{R}_{2} \mathrm{MnNiO}_{6}(\mathrm{R}=\mathrm{Pr}, \mathrm{Sm}$, and Ho) perovskite in aqueous potassium hydroxide[27], $\mathrm{Xu}$ et al. used the sol-gel method to synthesize the $\mathrm{A}_{2} \mathrm{NiWO}_{6}(\mathrm{~A}=\mathrm{Ca}$, $\mathrm{Sr})$ nanorods[28], and the solid-state reaction method for the preparation of $\mathrm{A}_{2} \mathrm{FeMoO}_{6}(\mathrm{~A}=\mathrm{Ba}, \mathrm{Sr}$, $\mathrm{Ca}$ ) in vacuum-sealed silica bulb, with precursors $\mathrm{BaO} / \mathrm{SrO}, \mathrm{Fe}_{2} \mathrm{O}_{3}, \mathrm{MoO}_{3}$, and metallic Mo mixed stoichiometrically by performing heat treatments ranging from 900 to $1000{ }^{\circ} \mathrm{C}$ with intermediate grinding[23-25, 29]. These materials had various technological applications such as magnetoelectronic devices because of their giant magnetoresistance (GMR)[30] used in the heads of hard disk drives [31], solar cells [32], solid oxide fuel cells [26, 33], and membranes with selective permeability [34]. Due to their unique properties, perovskite-based photocatalysts promising candidate for photocatalytic degradation for different dyes. Peng et al synthesized $\mathrm{LaFeO}_{3} /$ montmorillonite nanocomposites for photocatalytic dye degradation of rhodamine $\mathrm{B}$ under visible light irradiation, their degradation rate approximately $99.35 \%$ [35] and $\mathrm{La} 0.7 \mathrm{Sr} 0.3 \mathrm{MnO}_{3}$ nano-perovskites used for photocatalytic degradation of methyl orange (MO)[36] and $\mathrm{LaFeO}_{3}$ perovskites/Reduced graphene composites prepared for methylene blue under visible light irradiation[37]. Furthermore, the catalytic behavior of double perovskite structures depends on metals. Thus, the photocatalytic properties of the double perovskite structure can be boosted by the doping of different types of metals in the lattice structure[38, 39]. In this work, we reported double perovskite oxide $\left(\mathrm{Ba}_{2} \mathrm{TiMoO}_{6}\right)$ was synthesized by the solid-state reaction method and doped cerium element $\left(\mathrm{Ce}^{3+}\right)$ with different concentration $(1 \%, 3 \%, 5 \%$ and 7\%) and investigated experimentally by using Scanning Electron Microscopy, Transmission Electron Microscopy, X-Ray Diffraction, Fourier transform infrared spectroscopy to study the evolution of its structural properties as a function of the Ce doping percentage. The optical properties were determined by studying the optical reflection, the band gap energy, the refractive index, the Urbach energy and the photoluminescence and the photocatalytic activity. 


\section{Experimental Section}

\subsection{Chemicals and materials}

Barium oxide $(\mathrm{BaO})$ and Methyl Blue were bought from Sigma-Aldric. Titanium dioxide $\left(\mathrm{TiO}_{2}\right)$, Molybdenum trioxide $\left(\mathrm{MoO}_{3}\right)$, hydrogen peroxide $\left(\mathrm{H}_{2} \mathrm{O}_{2}\right)$ and Cerium oxide $\left(\mathrm{CeO}_{2}\right)$ were purchased from Kanto Chemical Co., Daejung Chemicals \& Metals Co., respectively. All the chemicals were no need further purification.

\subsection{Synthesis method}

A series of $\mathrm{Ba}_{2} \mathrm{TiMoO}_{6}$ doped with cerium element $\left(\mathrm{Ce}^{3+}\right)$ of different atomic percentage $\mathrm{x}=0,1,3,5,7 \%$ were synthesized by solid-state reaction. Pure commercial barium oxide $(\mathrm{BaO})$ (Sigma-Aldrich, 99.99\%), titanium dioxide $\left(\mathrm{TiO}_{2}\right)$ (Kanto Chemical Co, 99.1\%), Molybdenum trioxide $\left(\mathrm{MoO}_{3}\right)$ (Daejung Chemicals \& Metals Co., 99.5\%), and Cerium oxide $\left(\mathrm{CeO}_{2}\right)$ (Kanto Chemical Co, 99.99\%), were ground thoroughly in high-energy ball milling apparatus (Retsch, Emax) with $1000 \mathrm{rpm}$ speed. The obtained homogeneous powders were pelletized and heated gradually under air atmosphere to $1000{ }^{\circ} \mathrm{C}$ at a ramp speed of $20^{\circ} \mathrm{C} / \mathrm{min}$ and annealed for $60 \mathrm{~min}$ duration at $1000{ }^{\circ} \mathrm{C}$ and cooled to room temperature gradually in the furnace with a cooling rate of $5{ }^{\circ} \mathrm{C} / \mathrm{min}$ and ground for 1 hour to obtain fine powder. The annealed pellets were grounded manually for 1 hour, pelletized and undergone second annealing operation according to the same thermal previous cycle to homogenize the powder before calcination. Finally, the nano powders formed in a quasi-uniform shape were calcined at $600{ }^{\circ} \mathrm{C}$ for 2 hours and, prepared samples are labeled cb0, cb1, cb3, cb5 and cb7 respectively.

\subsection{Characterization techniques}

The surface morphology prepared compound was analyzed via scanning electron microscope (20 kV SEM, FEI, Inspect S50) and Transmission electron microscope (80 kV TEM, FEI, Morgagni 268). Thermal stability and degradation were investigated in thermal gravimetric and differential thermogravimetric (Shimadzu DTG-60H), instrument in the rang $20-600{ }^{\circ} \mathrm{C}$ at a rate of $12{ }^{\circ} \mathrm{C} / 5 \mathrm{~min}$ under air atmosphere. The crystal structures were carried out using an X-Ray diffractometer (XRD-7000, Shimadzu) at $40 \mathrm{kV}$ and $30 \mathrm{~mA}$ with $\mathrm{Cu}-\mathrm{K} \alpha$ radiation $(\lambda=1.5406 \AA$ ) in the $2 \theta$ range from $20^{\circ}$ to $70^{\circ}$ with a scanning speed of $0.02^{\circ} \%$. An infrared Fourier transform spectrophotometer (IRAffinity-2, Shimadzu) in the 400-4000 cm-1 wavenumber range with $2 \mathrm{~cm}$ 1 resolutions, was used to specify the intramolecular bonds. UV-VIS-NIR spectrophotometer (3700, Shimadzu) was used to accomplish diffuse reflectance spectroscopy in the 200-900 nm 
wavelength range. Spectrofluorometer 8500 (Fluorolog FL3-iHR, HORIBA Jobin Yvon) was used to accurate the photoluminescence (PL) emission spectra. UV-Vis double beam PC 8 scanning auto cell spectrophotometer (UVD-3200) was used to measure the photocatalytic efficiency in the range 400-800 nm wavelength with $15 \mathrm{~W}$ halogen lamp for UV-light source.

\subsection{Photocatalytic activity}

To investigate the photocatalytic activity properties of the prepared samples, photocatalytic degradation of methane blue dye (MB) was used with the aid of hydrogen peroxide (H2O2) under controlled conditions of visible light irradiation. The MB solution was prepared by dissolving $1 \mathrm{mg}$ Methylene Blue powder in $50 \mathrm{ml}$ hydrogen peroxide $(0.3 \%)$ and stirred $10 \mathrm{~min}$ in ultrasonic bath at room temperature. $2 \mathrm{mg}$ prepared compound was homogeneously dispersed in the MB solution and stirred for $10 \mathrm{~min}$ in the ultrasonic bath at room temperature. After the dispersion, the prepared (MB, photocatalyst) solution was stirred magnetically and exposed to visible light irradiation provided by a halogen lamp. UV-Vis double beam PC 8 scanning auto cell spectrophotometer (UVD-3200) was used to measure the photocatalytic activity. Samples were collected every 15 min and then centrifuged for 5 min to Eliminate any suspended particles. All samples were irradiated for $120 \mathrm{~min}$.

\section{Results and Discussion}

\subsection{Structur and morphological investigation}

The crystal structure and composition of pure and the Ce-doped $\mathrm{Ba}_{2} \mathrm{TiMoO}_{6}$ samples were characterized by using XRD measurement. Fig.1 shows the XRD patterns which affirms the tetragonal structure with the space group symmetry $\mathrm{P} 4 / \mathrm{mmm}$ of pure and Ce-doped $\mathrm{Ba}_{2} \mathrm{TiMoO}_{6}$. The peaks around $2 \theta$ of $29.08^{\circ}, 31.80^{\circ}, 41.64^{\circ}, 45.32^{\circ}, 51.56^{\circ}, 60.91^{\circ}$ and $68.31^{\circ}$, which can be indexed to the characteristic peaks of (110), (103), (114), (105), (115), (116) and (206) respectively. Moreover, the factor of tolerance of perovskite was determined to be 1.04 . The rate at which angles shift and become higher was carefully looked at in the main (110) peak, and it showed that the lattice shrunk caused by the substitution occurring in the cerium of A-site cation (Ba-site). On the other hand, the peak of (110) slightly shifts towards a lower angle, which could be caused by the presence of the smaller $\mathrm{Ce}^{4+}\left(\mathrm{CN}=6, \mathrm{r}_{\mathrm{Ce}}{ }^{4+}=0.87 \AA\right)$ in the place of $\mathrm{Ti}^{4+}\left(\mathrm{r}_{\mathrm{Ti}}{ }^{4+}=\right.$ $0.605 \AA, \mathrm{CN}=6$ at B-site [40]. The doping of Ce is very effective when there is no alteration of the structure of the crystal of the parent $\mathrm{Ba}_{2} \mathrm{TiMoO}_{6}$. However, an observation on the effect of the diffraction intensity peaks for the Ce-doped $\mathrm{Ba}_{2} \mathrm{TiMoO}_{6}$ is weakened with an increasing $\mathrm{Ce}$ 
content. There was an indication of some changes occured in the crystal sizes. Fig.2 illustrates the overall morphology of the prepared sample obtained by Scanning Electron Microscopy which exhibits the grains spread randomly and distribute themselves in different positions within the matrix. Also, the grains show irregular shapes, which appear to be grouped.

The images reveal porous materials constituted of fine, mostly spherical-shaped and irregularly distributed grains. The morphology of samples shows no significant changes apart from the size of the particles $[41,42]$. After the Ce doping, the grouped grains gradually began to reduce in size. Finally, introducing Ce additives can reduce grain grouping and size while improving their dispersity [43]. Fig.3 (a-e) shows transmission electron microscopy (TEM) that further certify the morphology and shape of the pure and Ce-doped $\mathrm{Ba}_{2} \mathrm{TiMoO}_{6}$ after heat treatment at $1000{ }^{\circ} \mathrm{C}$. Fig.3 (a) indicates that the pure $\mathrm{Ba}_{2} \mathrm{TiMoO}_{6}$ particles are seen to have dark image compounds that are almost quasi-spherical shaped and highly agglomerated. Fig.3(b-c) shows that after modification with cerium ions, the samples show similar nanostructures to the pure $\mathrm{Ba}_{2} \mathrm{TiMoO}_{6}$. Fig.3 (d-e) reveals that different particle aggregates are of different shapes size, which is not homogeneous in size. Using the image $\mathrm{J}$ software, the average size particle approximately 8-22 $\mathrm{nm}$, which showed a good distribution on the smooth surface [44]. Moreover the total surface area of the prepared compound was determined by using the Brunauer, Emmet and Teller (BET) theory. It consists to measure the amount of certain gas such as hydrogen which is adsorbed on the whole surface at very low temperature (-1960C), and the total surface area can be estimated according to:

$$
\mathrm{S}=\mathrm{Xm} \cdot \mathrm{N} \cdot \mathrm{Am} \cdot 10^{-20}\left(\mathrm{~m}^{2} \cdot \mathrm{g}^{-1}\right)
$$

where $\mathrm{Xm}$ is the monolayer capacity (moles per gram of solid), $\mathrm{N}$ is Avogadro's constant (6.023.1023 molecules per mole) and Am is the molecular cross-sectional area of the adsorbate, i.e., the area which an adsorbed molecule occupies on the surface of the solid in a complete monolayer $(\AA 2)$. The obtained results are listed in Table 1. It shows that the surface area increases with the Ce percentage from $1.552 \mathrm{~m}^{2} . \mathrm{g}^{-1}$ for the pure $\mathrm{Ba}_{2} \mathrm{TiMoO}_{6}$ to $2.229 \mathrm{~m}^{2} \cdot \mathrm{g}^{-1}$ for that Ce doped $7 \%$ indicating that the grain size decreasing with Ce percentage.

Fourier Transform Infrared Spectroscopy (FTIR) analysis use for functional groups and characterizing covalent bonding information of the prepared compound. Fig.4 investigated the FTIR spectra of pure $\mathrm{Ba}_{2} \mathrm{TiMoO}_{6}$ and Ce doped $\mathrm{Ba}_{2} \mathrm{TiMoO}_{6}$ samples in the range 4000-400 cm-1. A broad absorption peaks between 438 and $1031 \mathrm{~cm}^{-1}$ are ascribed to the metal oxides of M-O along the polar $\mathrm{c}$ axis of their octahedral structure due to the elongation mode of the Ti-O, Mo-O, 
and $\mathrm{Ba}-\mathrm{O}$ bond ubiquitous in the specimen. The other vibrations are overlapped by the $\mathrm{Ti}-\mathrm{O}$ stretching vibrations in the range 438 to $886 \mathrm{~cm}-1$. The $\mathrm{O}-\mathrm{Ti}$ - bending vibrations of $\mathrm{TiO}_{6}$ results in the bands observed at $438 \mathrm{~cm}-1$ for all prepared composites respectively. On the other hand, Mo-O bending vibrations characteristic of $\mathrm{MoO}_{6}$ result in the bands observed at 886 and $1031 \mathrm{~cm}^{-}$

1. The resultant bands are affiliated with the octahedral in the perovskite structure [45]. The vibration $438 \mathrm{~cm}^{-1}$, can be denoted in all the curves. As a result, in the Ti-O-Mo bond, the vibrations can be associated with its asymmetric stretching and bending that leads to the formation of the $\mathrm{Mo} / \mathrm{TiO}_{6}$ octahedral structure. $\mathrm{Ba}-\mathrm{O}-\mathrm{Ba}$ bending can be inferred from the strong peak centered at $886 \mathrm{~cm}-1$. In the spectra, the absorption bands show at $1436 \mathrm{~cm}^{-1}$ the bound originate from the $\mathrm{C}-\mathrm{O}$ stretching vibration. The stretching modes of vibrations are both asymmetric and symmetric for $\mathrm{C}=\mathrm{O}$ bonds. In pure samples, the $\mathrm{O}-\mathrm{C}-\mathrm{O}$ bond may exist in forms such as segregated phases of carbonates, formed during the calcination [46]. The existence of $\mathrm{CO}_{2}$ molecules in the air is assigned to the absorption band $2340 \mathrm{~cm}^{-1}$ [47]. The exposure of perovskites to environmental humidity results in the broad peak range of $\left(2952-3687 \mathrm{~cm}^{-1}\right)$, which gives an inference to the $\mathrm{O}-\mathrm{H}$ stretching vibration of water. Thermo-Gravimetric Analysis (TGA) technique used for the investigations on the thermal stability of pure $\mathrm{Ba}_{2} \mathrm{TiMoO}_{6}$. The broad exothermic peaks observed in the DTA curves are attributed to the decrease in weight of $\mathrm{Ba}_{2} \mathrm{TiMoO}_{6}$ in the TGA curves below $250{ }^{\circ} \mathrm{C}$. The formation of phase results in the stagnation of the compound's weight between temperatures of 38.89 and $203.7^{\circ} \mathrm{C}$.

Fig.5 shows the temperature-dependent weight loss of $\mathrm{Ba}_{2} \mathrm{TiMoO}_{6}$ pure, which concludes that evaporation is responsible for the weight loss below $250{ }^{\circ} \mathrm{C}$ (step I). Decreased oxygen content in the material is responsible for the sharp drop occurring around $400-700^{\circ} \mathrm{C}$ (step II). Prolonged analysis at $1000{ }^{\circ} \mathrm{C}$ (step III) shows a gradual decrease in weight implying the formation of more oxygen vacancies [48]. Similarly, the weight loss correlates with the discharge of oxygen atoms and the formation of oxygen vacancies in $\mathrm{Ba}_{2} \mathrm{TiMoO}_{6}$. According to the curve, the Ce doped $\mathrm{Ba}_{2} \mathrm{TiMoO}_{6}$ underwent decomposition at 600 and $720{ }^{\circ} \mathrm{C}$ (exothermic peaks) and $783.11{ }^{\circ} \mathrm{C}$ (endothermic peaks). After $910^{\circ} \mathrm{C}$, however, shows without weight loss is a result of the formation of the crystalline phase [49].

\subsection{Optical properties}

Synthesized $\mathrm{Ba}_{2} \mathrm{TiMoO}_{6}$ nanoparticles properties were analyzed using UV-Vis spectroscopy, where the optical diffusion reflectance was performed in the spectral range 200-800 
nm. The information presented relative information on the band gap, refractive index, Urbach energy and electron transitions in materials.

The estimated band gap energy was established Kubelka-Munk function (Eq. 1):

$$
[F(R) h v]^{1 / n}=A\left(h v-E_{g}\right)
$$

$\mathrm{F}(\mathrm{R})$ represents the reflectance function calculated from the reflectance spectrum.

$$
F(R)=\frac{(1-R)^{2}}{2 R}
$$

The symbols are represented as follows, $\mathrm{R}$ is the reflectance, $\mathrm{n}$ is equal to $1 / 2$ or 2 which depends on the electron transition band gaps for both direct and indirect. Also, hv is the photon energy expressed in $\mathrm{eV}, \mathrm{A}$ is the constant parameter giving the transition probability. The transition probability is reflected from the valence band electron to the conduction band [50,51]. The tangent intercept to the $\mathrm{X}$-axis gives a good approximation to the energy band gap of the as-prepared samples. The curves of Fig.6 show the Kubelka-Munk plots for the direct and indirect transition for all the prepared samples. Fig. 6 indicated that the more the concentration of cerium increases in $\mathrm{Ba}_{2} \mathrm{TiMoO}_{6}$ the more the gap energy decreases. It is not a homogeneous process because of certain factors: (i) The first factor is the substitution of $\mathrm{Ce}^{3+}$ ions where they occupy the $\mathrm{B}$ sites; (ii) some structural defects can appear due to the corresponding charge unbalance; (iii) distortion of the crystal lattice. These are associated with stacking faults that result in Ce ions having a larger ionic radius (1.034 $\AA$ ) than Ti ions $(0.605 \AA$ ). The contribution of microstructural defects (Micro-strain and dislocation density) and the effects of the size of the particles also play an important role in reducing the band gap[52]. Table 2 exhibited that, there is a decrease in the band gap values whereby $\mathrm{Ba}_{2} \mathrm{TiMoO}_{6}$ has an indirect transition. For cb0, the indirect bandgap at relatively lower energy $3.51 \mathrm{eV}$, as compared to the direct bandgap, $3.60 \mathrm{eV}$. The transition in the UV spectra of cb1 exhibited the indirect bandgap when exposed to lower energy (3.41) as opposed to a direct bandgap (3.63). However, for cb3, an indirect band gap is noticed at a lower energy of $3.55 \mathrm{eV}$ than when applied to a direct band gap of $3.60 \mathrm{eV}$. The indirect transition in the UV spectra of cb5 is $3.44 \mathrm{eV}$, so at lower energies, cb5 exhibits an indirect band gap over a direct bandgap. Also, cb7 shows the indirect band gap at relatively lower energy, $3.41 \mathrm{eV}$, compared to the direct bandgap, $3.5 \mathrm{eV}$. The $\mathrm{Ba}_{2} \mathrm{TiMoO}_{6}$ is classified as the indirect electronic transition material, and its refractive index can be calculated using the following equation

$$
\frac{\mathrm{n}^{2}-1}{\mathrm{n}^{2}+2}=1-\sqrt{\frac{\mathrm{E}_{\mathrm{g}}}{20}}
$$


The intermediary levels in the bandgap area increase because of the effect of the impurity and alteration of the unit cell. There is a relationship between the Urbach tail and the width of the defect bands. Urbach energy is illustrated through this equation involving $\mathrm{C}$ as a constant and $\mathrm{E}_{U}$ the Urbach energy

$$
\ln \alpha=\frac{h v}{E_{U}}+C
$$

It is possible to graph $\ln [F(R)]$ vs. photon energy, hu. based on the absorption nature of the coefficient $\alpha$ which is proportional to absorbance A (or F(R) in DRS mode). The reciprocal gradient of the linear part of the plot corresponds with the $\mathrm{E}_{\mathrm{U}}$ value. The dimension of energy results from the relationship between the width of the localized levels and the $\mathrm{E}_{\mathrm{U}}$ which is regarded as a precious factor that illustrates the possible defects [53, 54]. The Urbach energy curves of entire samples are shown in Fig.7, which shows an increase from $106.6 \mathrm{meV}$ in cb0 to $114.7 \mathrm{meV}$ in cb1 and later on, reduces to $71.1 \mathrm{meV}$ for about $\mathrm{cb} 3$ and rises to $106.5 \mathrm{in} \operatorname{cb} 5$ which reduces to $99.4 \mathrm{in}$ cb7. All the modifications within the structural disorder contribute to other changes in the bandgaps. Modifications in the Urbach tail width led to the disparity in the bandgap. The enhancement/reduction in atomic structural disorder is facilitated by the increase/decrease of $\mathrm{E}_{U}$ which is associated with the decrease/increase of optical bandgap with rising Ce concentration.

\subsection{Photoluminescence analysis}

Photoluminescence (PL) emission is the result of the recombination of electrons and holes in photocatalysts. To understand the behavior of the aforementioned photo-generated holes and electrons, it is necessary to comprehend the fundamentals of the PL spectra [50]. For the synthesized perovskite $\left(\mathrm{Ba}_{2} \mathrm{TiMoO}_{6}\right)$ infused with a given amount of $\mathrm{Ce}$, the emission band of its spectrum extends from the UV to the Visible region 200 to $800 \mathrm{~nm}$ of the electromagnet spectrum as shown in Fig.7. Cerium ions have profound chemical properties (their redox chemistry is exceptional and their oxygen storage capacity is remarkable). As a result, they are useful ions used as dopants to accelerate photocatalytic activities by trapping and slowing down electron-hole recombination.

The emission from more than one energy level results in an emission spectrum with a broad emission peak. As shown in Fig.7, the emission spectrum has a maximum intensity at $426.67 \mathrm{~nm}$ wavelength, conserve the same for all the prepared samples; and the emitted intensity was reduced (extinguished) while the Ce percentage was enhanced. The observation suggests that the Ce ion 
doping only affects the intensity of the PL spectra. As a result, it does not lead to a new lightemitting phenomenon and the Ce-doped $\mathrm{Ba}_{2} \mathrm{TiMoO}_{6}$ samples exhibit lower photocatalytic activity compared to its pure one.

The high intensity is ascribed to the electron transition from $5 \mathrm{~d}\left(\mathrm{Ce}^{3+}\right.$ lowest energy level) to ${ }^{2} \mathrm{~F}_{5 / 2}-{ }^{2} \mathrm{~F}_{7 / 2}$ manifolds split by spin-orbit coupling. The radiative recombination of a photogenerated hole with electron results in an emission spectrum whose peak is centered at $\sim 426.67$ $\mathrm{nm}$ known as violet emision. The photo-generated hole recouples with an electron that occupies various surface defects. The surface defects include oxygen vacancies, F-centers (oxygen ion void filled by a pair of electrons)/F-centers (oxygen ion void filled by solitary electrons)/surface states.

\subsection{Photocatalytic Activity Test}

To investigate the photocatalytic activity properties of the prepared samples, photocatalytic degradation of methane blue dye (MB) was used hydrogen peroxide $\left(\mathrm{H}_{2} \mathrm{O}_{2}\right)$ under controlled conditions of visible light irradiation (with400-800 nm wavelength range). Fig.8(a, b) shows the obtained spectrum for all the prepared photocatalyst. It can be denoted that all the spectra are characterized by maximum peak at $660 \mathrm{~nm}$ and a shoulder peak at $614 \mathrm{~nm}$. From the two aforementioned peaks, it was clear that their absorbance decreased with the increase in irradiation time. There are no new absorption bands emanated in the spectra of cb1, cb3, cb5, and $\operatorname{cb} 7$ compared to that of cb0 during the photocatalytic process. The photocatalytic efficiency of the prepared catalysts can be estimated by measuring its degradation effect on the MB solution by the following expression $[55,56]$ :

$$
\mathrm{D}=\frac{\mathrm{C}_{0}-\mathrm{C}_{\mathrm{t}}}{\mathrm{C}_{0}}
$$

Where $C_{0}$ indicates the initial concentration $\left(C_{0}=1\right)$ and $C_{t}$ refers to the concentration after a certain time of reaction. The degradation rate of the prepared photocatalysts for various $\mathrm{Ce}$ percentage and irradiation durations was depicted in Table 3 and plotted in Fig.9. The experimental results demonstrated that MB hardly degraded within an irradiation period of $120 \mathrm{~min}$. All the doped samples are of higher photocatalytic activity compared to the undoped one and increase by increasing the Ce percentage. Under visible light of 120 minutes' irradiation duration, the degradation rate can reach $9 \%, 10.7 \%, 11.9 \%$ and $15.8 \%$ for the $\mathrm{cb} 1, \mathrm{cb} 3, \mathrm{cb} 5$, and $\mathrm{cb} 7$ photocatalysts; respectively. 
A further explanation of the proposed photocatalytic mechanism is given in Fig.10, which indicates that the catalyst absorbs light of the solar spectrum and creates photo-generated charge carriers (holes and electrons). Charge separation is caused by electrons transitioning from the low energy valence bands to higher energy conduction bands. The transition results in the formation of a positively charged hole. The aforementioned electrons and holes usually recombine quickly resulting in the decreased catalytic activity of the compound. The reduced activity implies that the doped compound experiences a lower photocatalytic activity compared to undoped one. Ce $4 \mathrm{f}$ level is crucial for photo-exited charge generation and transfer for the Ce-doped $\mathrm{Ba}_{2} \mathrm{TiMoO}_{6}$. The Ce 4f level also plays a key role in curtailing the recombination of electrons and holes. $\mathrm{Ce}^{3+}$ traps could be used as electron scavengers to trap electrons in the conduction band. Via oxidation, electrons trapped by $\mathrm{Ce}^{3+}$ ions are transferable to the adsorbed $\mathrm{H}_{2} \mathrm{O}_{2}$ through the equation:

$$
\mathrm{Ce}^{3+}+\mathrm{H}_{2} \mathrm{O}_{2} \rightarrow \mathrm{Ce}^{4+}+{ }^{\cdot} \mathrm{OH}+\mathrm{OH}^{-}
$$

The transfer results in the formation of a hydroxide radical $(\cdot \mathrm{OH})$. On the other hand, the highly reactive hydroxyl radicals $\left({ }^{\circ} \mathrm{OH}\right)$ are produced it reacts with the $\mathrm{MB}$ molecules allowing to its degeneration.

$$
\mathrm{MB}+\cdot \mathrm{OH} \rightarrow \text { degraded products }
$$

Therefore, increase the Ce-doping concentration enhances the number of the $\bullet \mathrm{OH}$ radical and so the photocatalytic efficiency.

\section{Conclusion}

In summary, we successfully synthesized a $\mathrm{Ba}_{2} \mathrm{TiMoO}_{6}$ doped with cerium element $\left(\mathrm{Ce}^{3+}\right)$ by solid-state reaction. SEM and TEM images clearly show that $\mathrm{Ba}_{2} \mathrm{TiMoO}_{6}$ almost quasispherical shaped and highly agglomerated, XRD and FTIR spectra results show an octahedral in the perovskite structure and cerium element $\left(\mathrm{Ce}^{3+}\right)$ successfully doped with $\mathrm{Ba}_{2} \mathrm{TiMoO}_{6}$. The photocatalytic performances $\mathrm{Ba}_{2} \mathrm{TiMoO}_{6}$ doped with cerium element $\left(\mathrm{Ce}^{3+}\right)$ were evaluated using methane blue (MB). It is clearly indicated that $\mathrm{Ba}_{2} \mathrm{TiMoO}_{6}$ promising candidate for photocatalysis under visible light irradiation. This satisfactory result shows that Perovskites materials can further be used for environmental-related applications. 
Figures

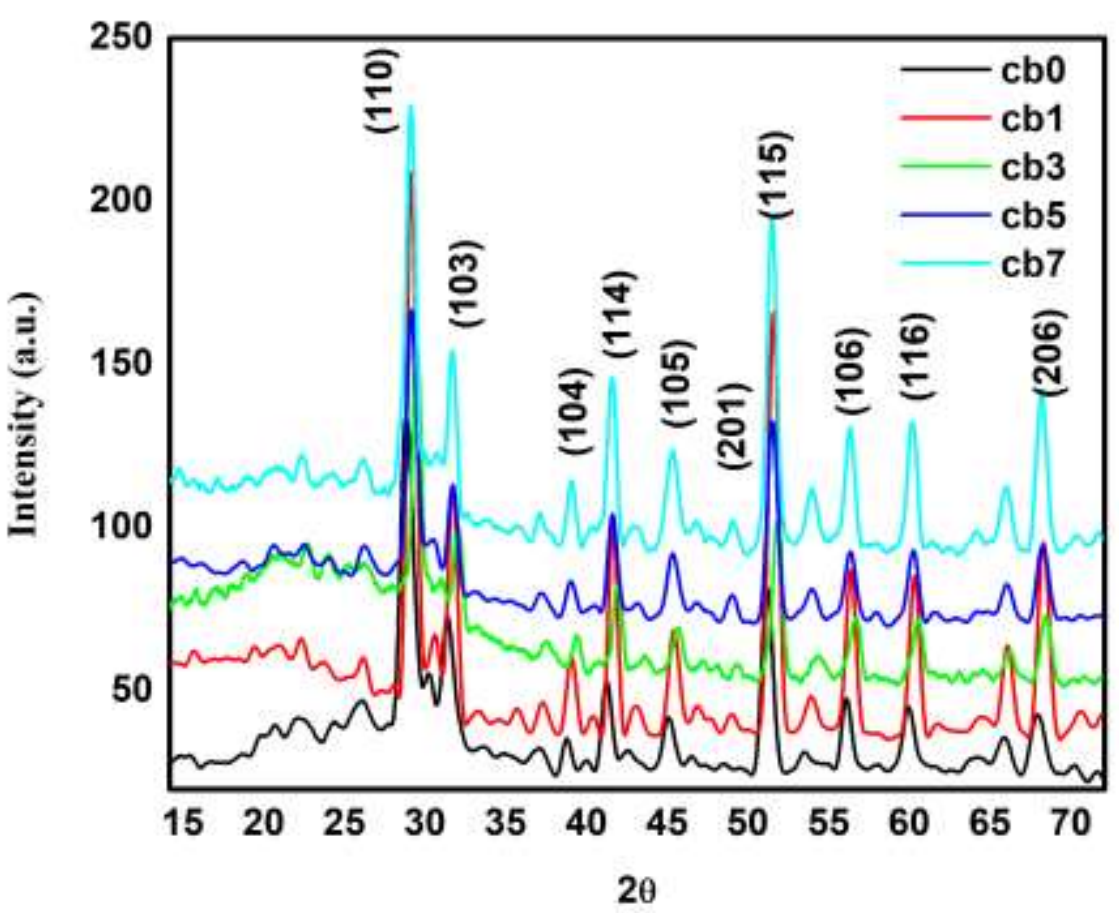

Fig.1. X-ray diffraction patterns for pure and Ce-doped $\mathrm{Ba}_{2} \mathrm{TiMoO}_{6}$ 

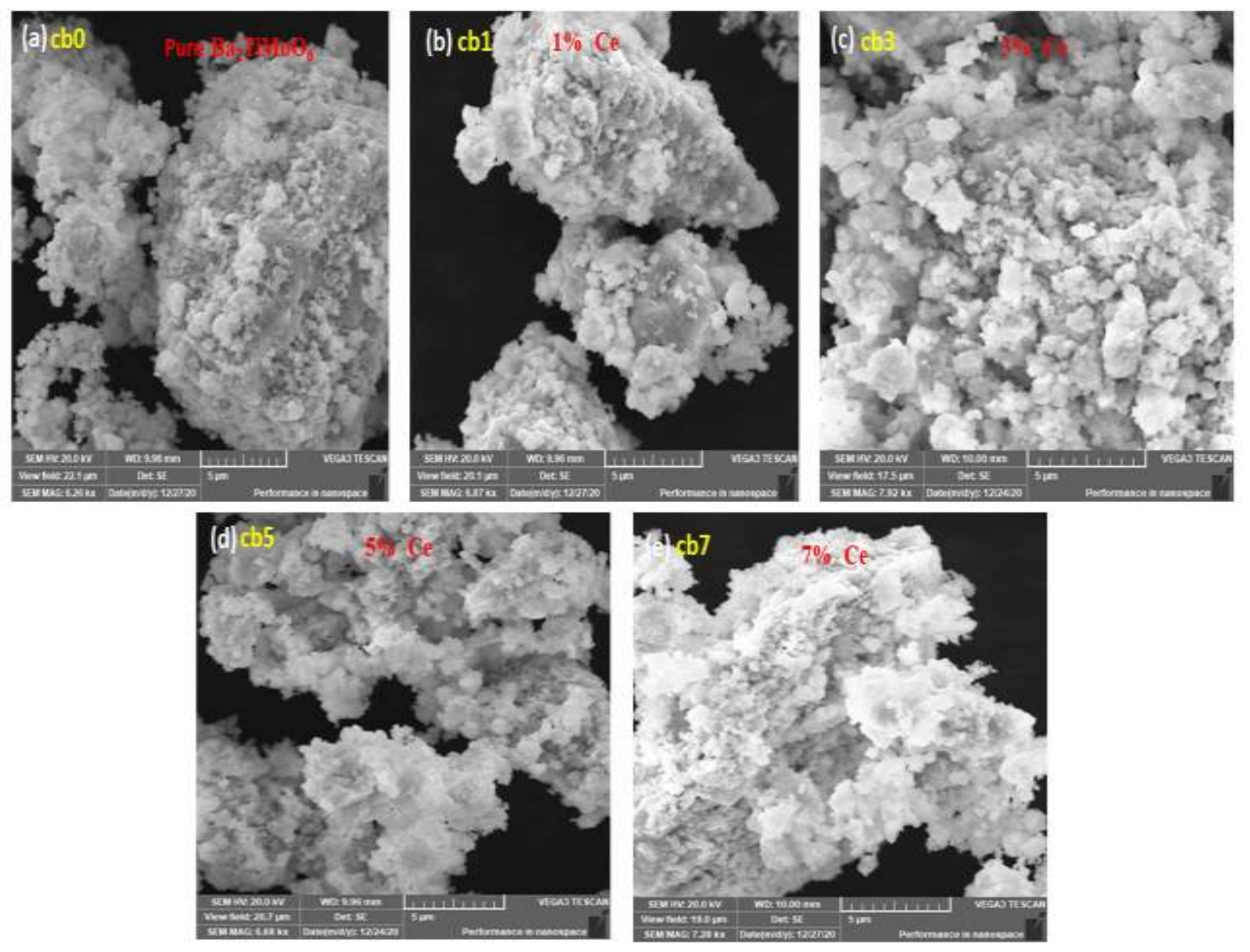

Fig.2. SEM images of (a) pure $\mathrm{Ba}_{2} \mathrm{TiMoO}_{6}$ (b) $1 \mathrm{wt} \%$ (c) $3 \mathrm{wt} \%$ (d) $5 \mathrm{wt} \%$ (e) $7 \mathrm{wt} \%$ Ce-doped $\mathrm{Ba}_{2} \mathrm{TiMoO}_{6} \mathrm{NPs}$ 

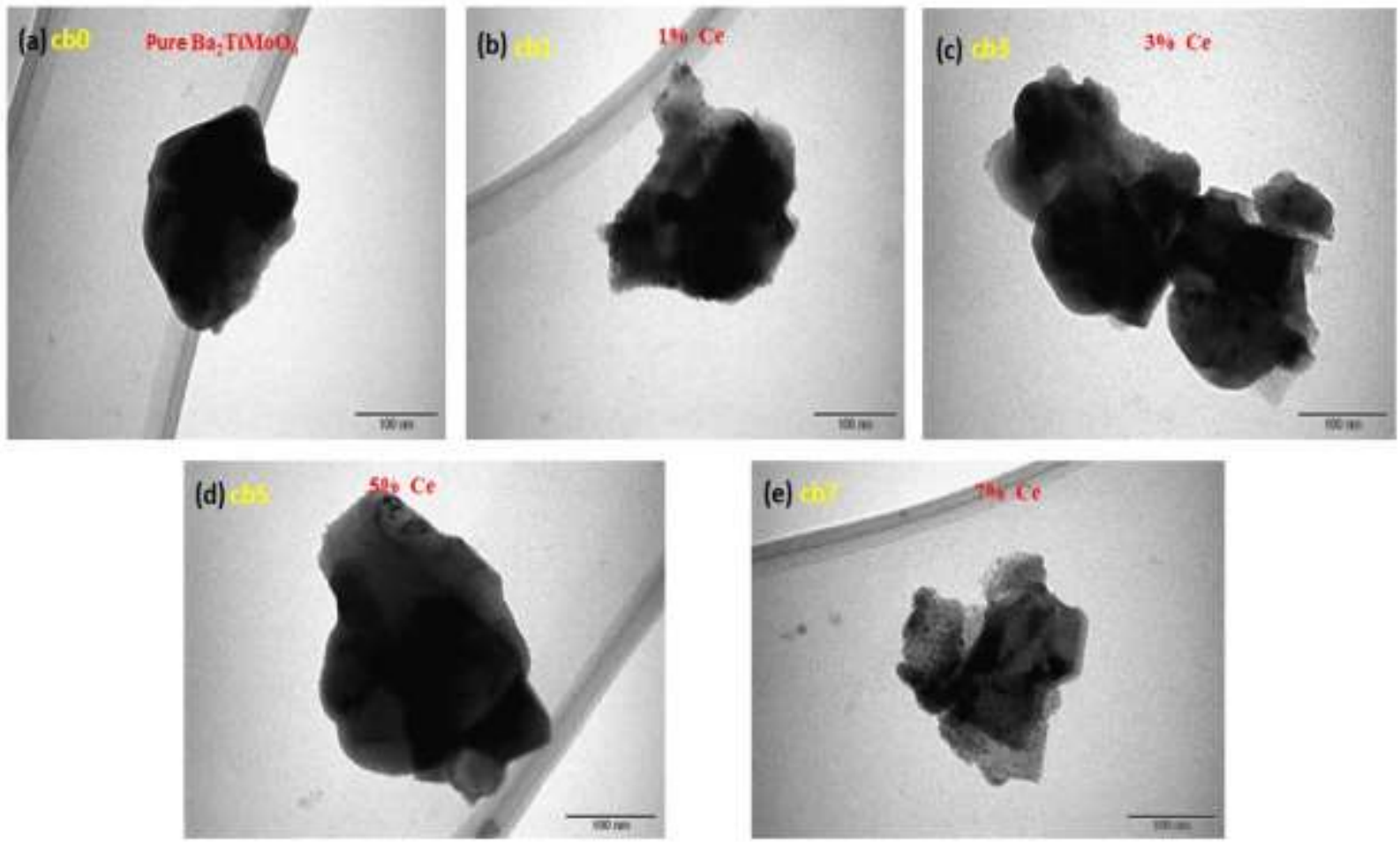

Fig.3. TEM images of (a) Pure $\mathrm{Ba}_{2} \mathrm{TiMoO}_{6}$ (b) $1 \mathrm{wt} \%$ (c) $3 \mathrm{wt} \%$ (d) $5 \mathrm{wt} \%$ (e) $7 \mathrm{wt} \%$ Ce-doped $\mathrm{Ba}_{2} \mathrm{TiMoO}_{6} \mathrm{NPs}$ 


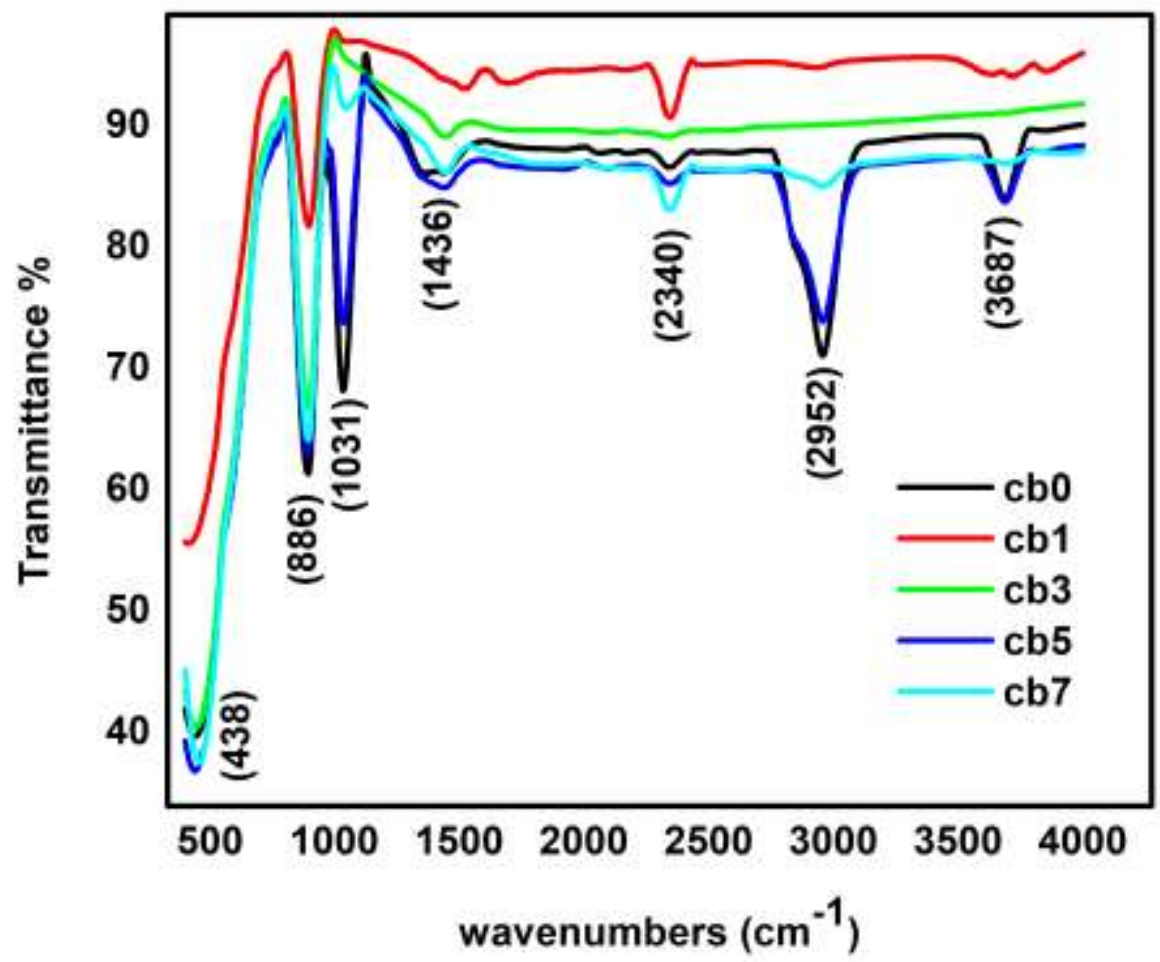

Fig.4. The FTIR spectra of pure and Ce doped $\mathrm{Ba}_{2} \mathrm{TiMoO}_{6}$ samples (range $4000-400 \mathrm{~cm}^{-1}$ ).

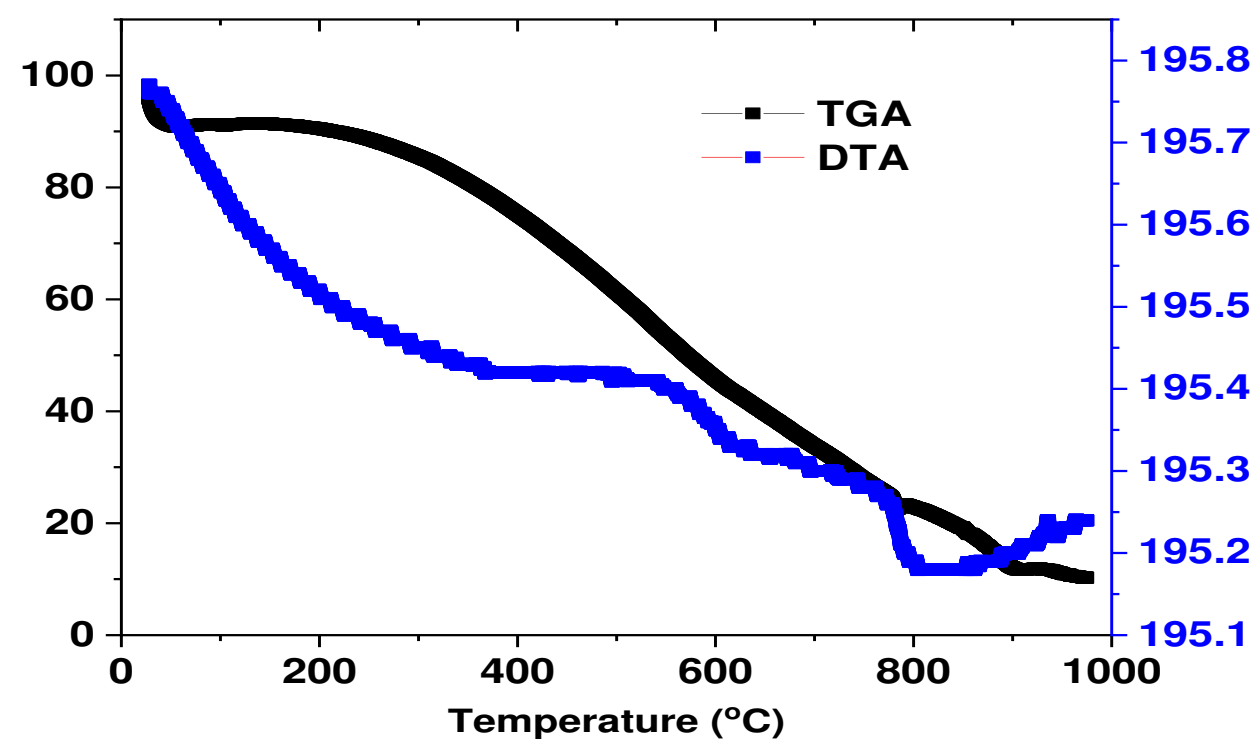

Fig.5. TGA and DTA of the pure $\mathrm{Ba}_{2} \mathrm{TiMoO}_{6}$ double perovskite. 

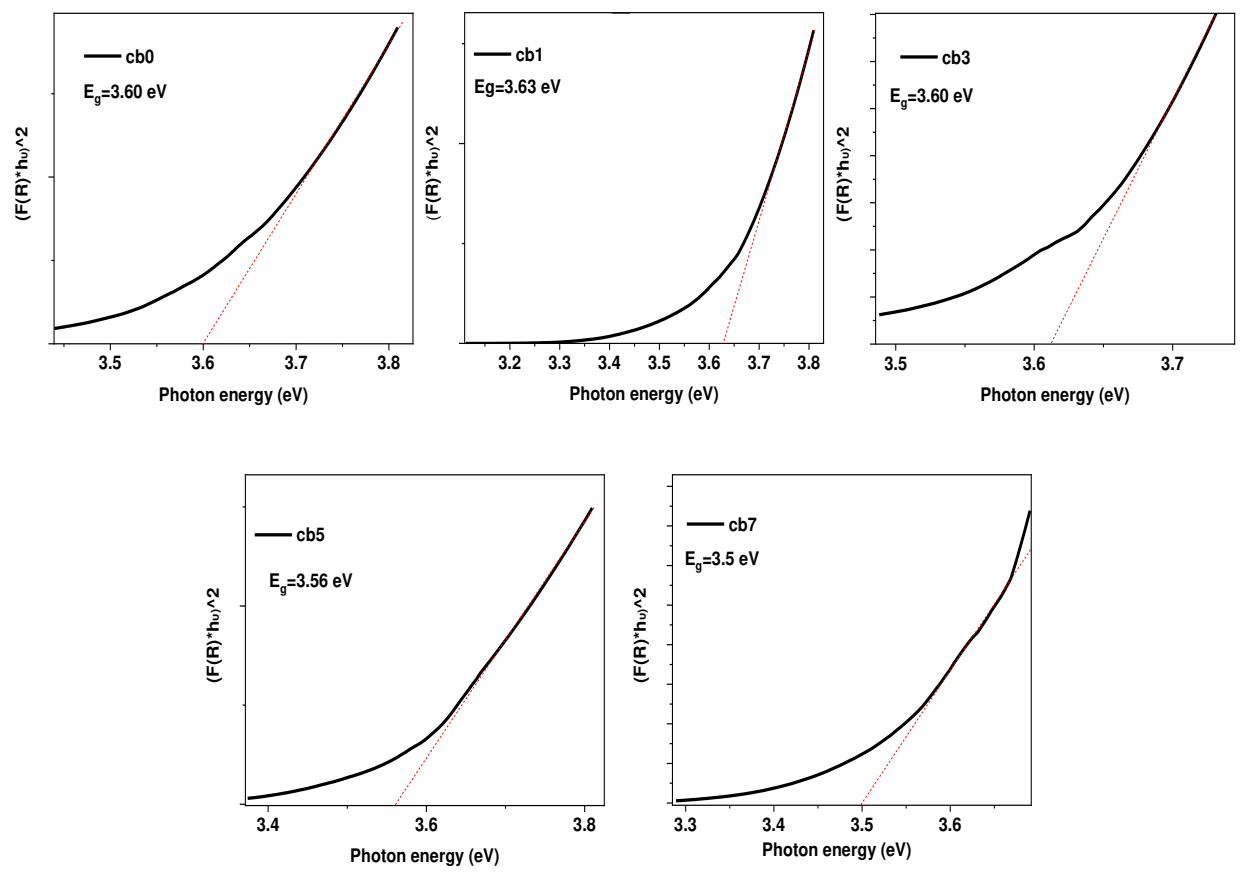

Fig.6 (a). Kubelka-Munk plots and direct-band gap values of the Pure $\mathrm{Ba}_{2} \mathrm{TiMoO}_{6}, 1 \%$, 3\%, 5\% and 7\% Ce-doped $\mathrm{Ba}_{2} \mathrm{TiMoO}_{6}$.
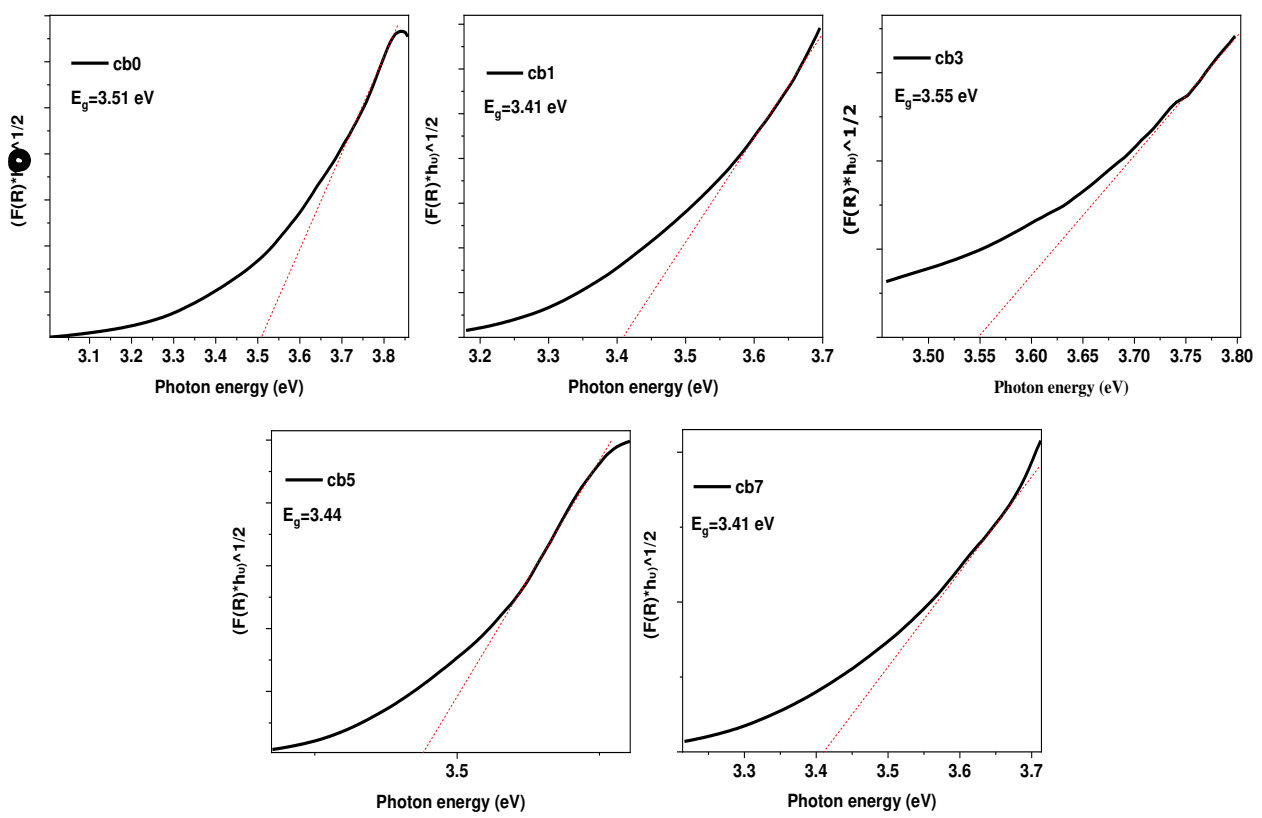

Fig.6 (b). Kubelka-Munk plots and indirect-band gap values of the Pure $\mathrm{Ba}_{2} \mathrm{TiMoO}_{6}, 1 \%, 3 \%$, $5 \%$ and $7 \%$ Ce-doped $\mathrm{Ba}_{2} \mathrm{TiMoO}_{6}$. 


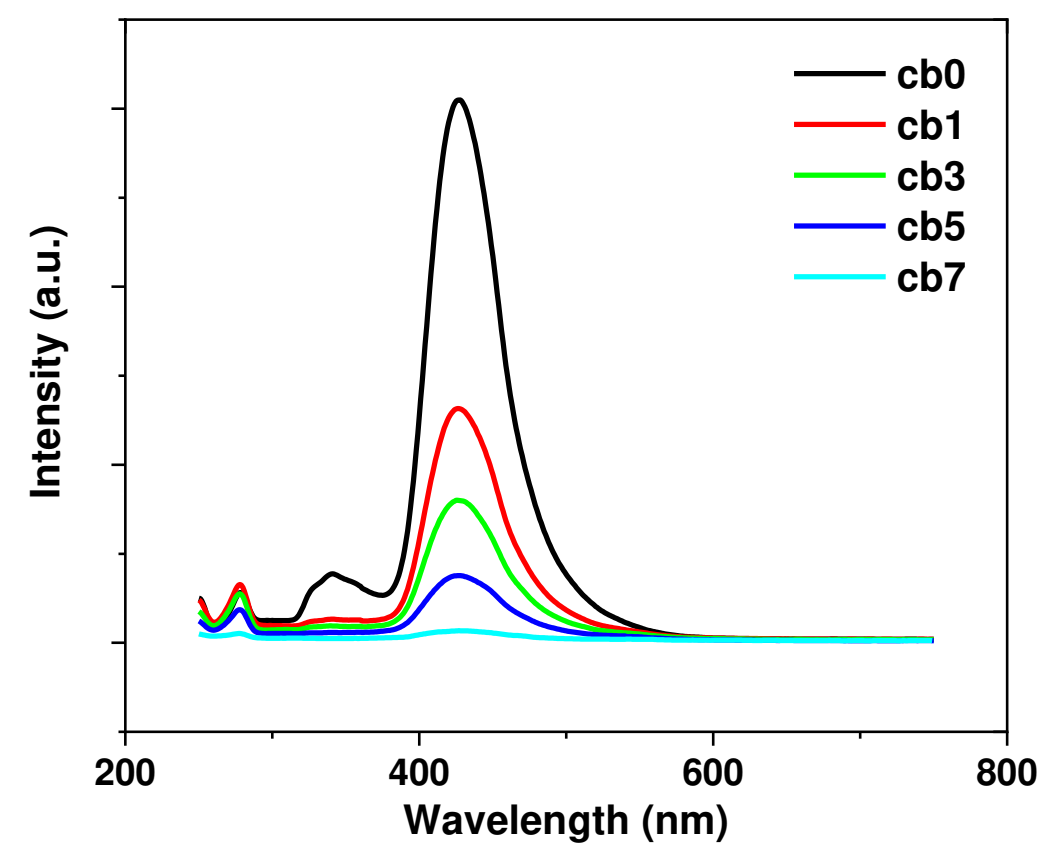

Fig.7. Photoluminescence spectra of pure and $\mathrm{Ce}$ doped $\mathrm{Ba}_{2} \mathrm{TiMoO}_{6}$
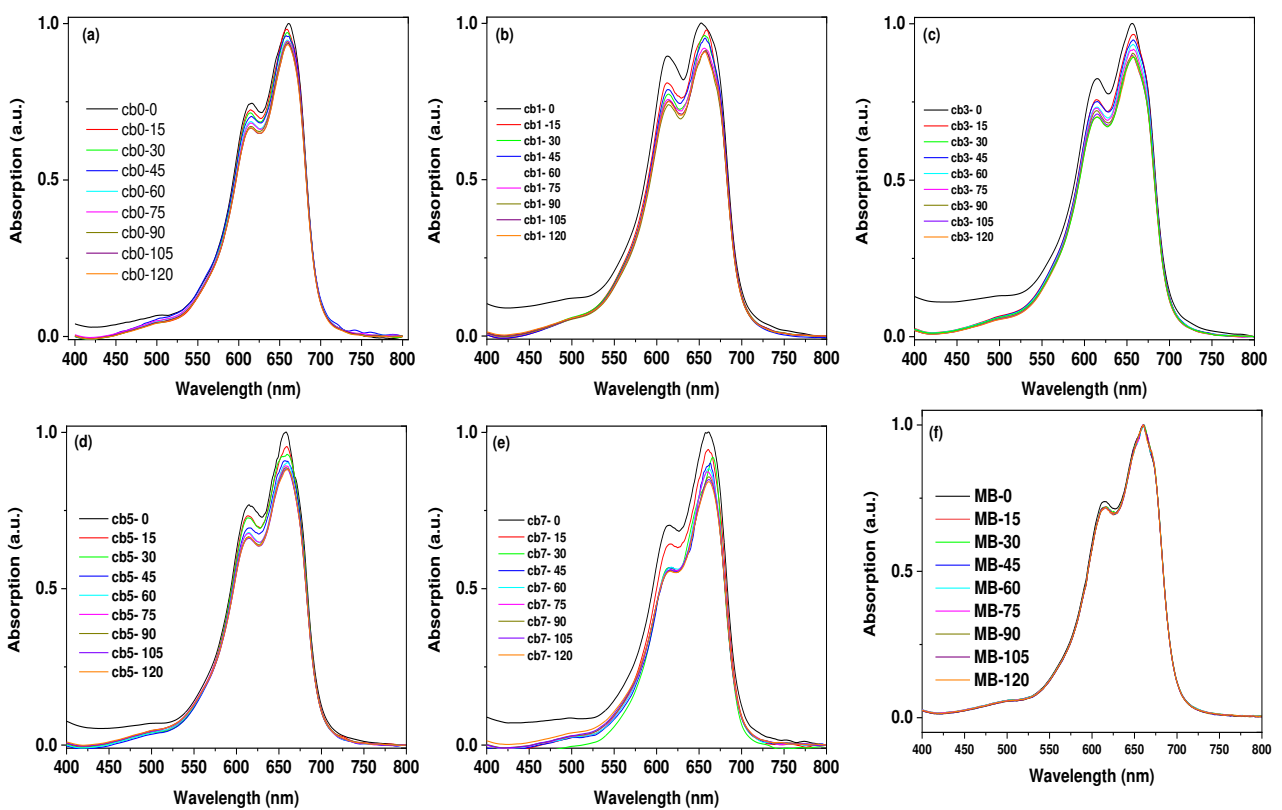

Fig.8. Degradation spectra of $\mathrm{MB}$ with $\mathrm{Ba}_{2} \mathrm{TiMoO}_{6}$ catalysts for different Ce concentrations (ae) and without any catalyst (f). 


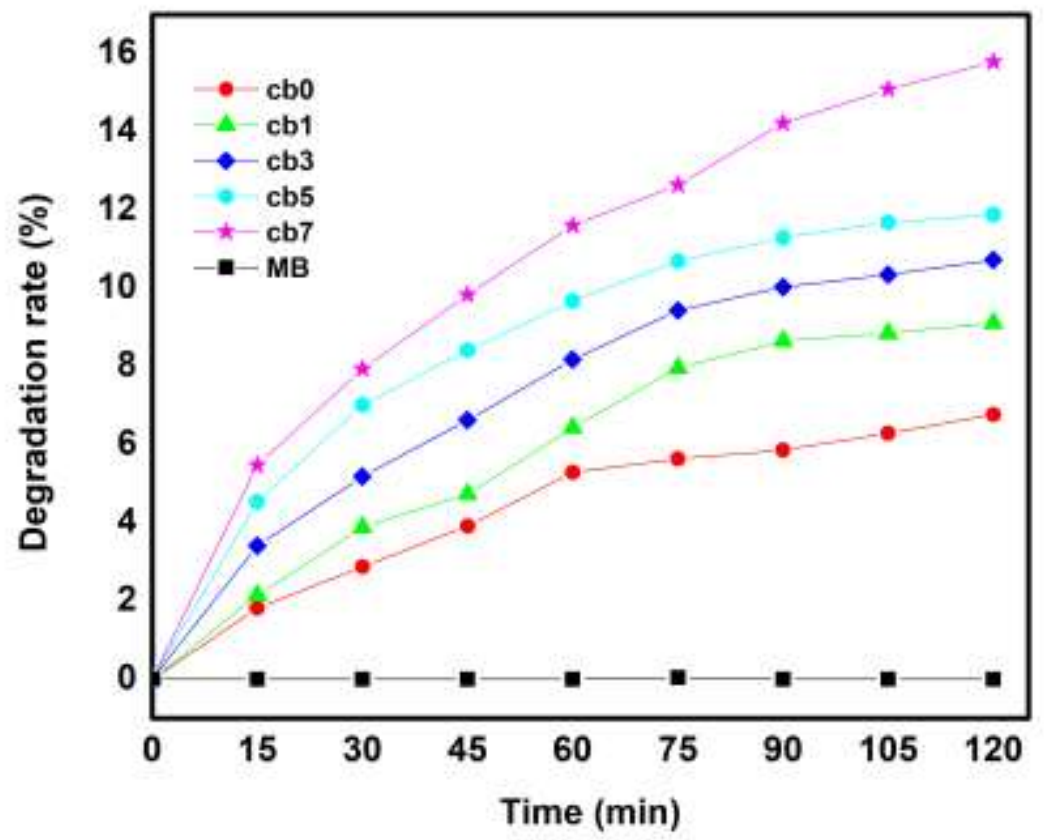

Fig.9. Degradation rate of the prepared samples versus time with different Ce doping percentages

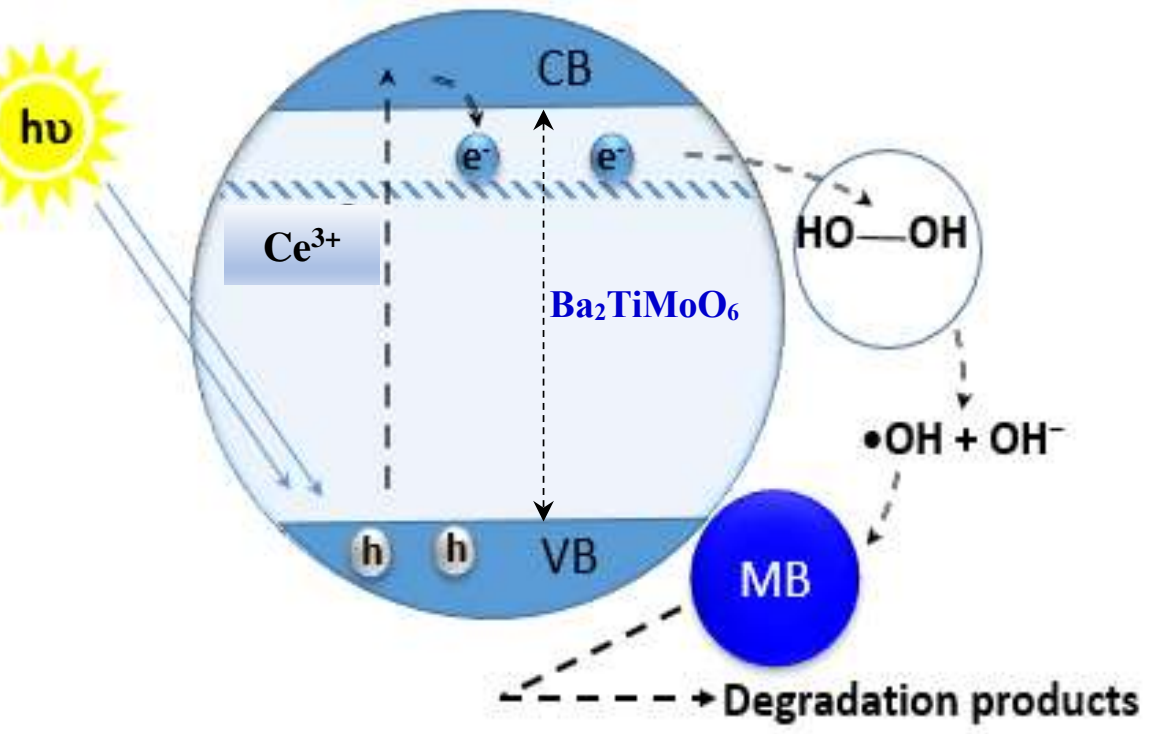

Fig.10. Photocatalytic mechanism for the degradation of $\mathrm{MB}$ by Ce-doped $\mathrm{Ba}_{2} \mathrm{TiMoO}_{6}$ 
Tables

Table 1. Surface area of the pure and Ce doped $\mathrm{Ba}_{2} \mathrm{TiMoO}_{6}$ double perovskite.

$\begin{array}{ll}\text { Sample ID } & \text { SA }\left(\mathbf{m}^{\mathbf{2}} \cdot \mathbf{g}^{-\mathbf{1}}\right) \\ \mathrm{Cb} 0 & 1.552 \\ \mathrm{Cb} 1 & 1.779 \\ \mathrm{Cb} 3 & 1.894 \\ \mathrm{Cb} 5 & 1.984 \\ \mathrm{Cb} 7 & 2.229\end{array}$

Table 2. Estimated refractive index.

\begin{tabular}{lllll}
\multirow{2}{*}{ Sample } & The refractive index & \multicolumn{2}{c}{ band gap (ev) } & Urbach energy \\
& & Direct & Indirect & (mev) \\
Cb0 & 2.274 & 3.60 & 3.51 & 106.62 \\
Cb1 & 2.277 & 3.63 & 3.41 & 114.72 \\
Cb3 & 2.279 & 3.60 & 3.55 & 71.14 \\
Cb5 & 2.290 & 3.56 & 3.44 & 106.55 \\
Cb7 & 2.294 & 3.5 & 3.41 & 99.40
\end{tabular}

Table 3. Degradation rate of the cb photocatalysts for various Ce percentage and irradiation durations.

$\begin{array}{lllllll}\text { Time }(\min ) & \text { MB } & \text { Cb0 } & \text { Cb1 } & \text { Cb3 } & \text { Cb5 } & \text { Cb7 } \\ 0 & 0 & 0 & 0 & 0 & 0 & 0 \\ 15 & 0.00339 & 1.817 & 2.149 & 3.411 & 4.54 & 5.473 \\ 30 & 0.00339 & 2.882 & 3.892 & 5.184 & 7.023 & 7.941 \\ 45 & 0.00339 & 3.916 & 4.737 & 6.628 & 8.416 & 9.839 \\ 60 & 0.00339 & 5.291 & 6.437 & 8.18 & 9.682 & 11.609 \\ 75 & 0.04923 & 5.638 & 7.962 & 9.438 & 10.701 & 12.643 \\ 90 & 0.00339 & 5.8642 & 8.657 & 10.039 & 11.303 & 14.227 \\ 105 & 0.00339 & 6.291 & 8.853 & 10.352 & 11.687 & 15.095 \\ 120 & 0.00339 & 6.766 & 9.117 & 10.729 & 11.884 & 15.794\end{array}$




\section{References}

[1] S. Porhemmat, A. Rezvani, M. Ghaedi, A. Asfaram, A. Goudarzi, Ultrasonic treatment of wastewater contaminated with various dyes using tin oxide hydroxide nanoparticles loaded on activated carbon: Synthesis, performance, mechanism and statistical optimization, Appl. Organomet. Chem. 31 (2017) e3860. https://doi.org/10.1002/aoc.3860

[2] A. Mittal, J. Mittal, A. Malviya, V. Gupta, Removal and recovery of Chrysoidine Y from aqueous solutions by waste materials, J. Colloid Interface Sci. 344 (2010) 497-507. https://doi.org/10.1016/j.jcis.2010.01.007

[3] P. Raizada, A. Kumar, V. Hasija, P. Singh, V. K. Thakur, A.A.P. Khan, An overview of converting reductive photocatalyst into all solid-state and direct Z-scheme system for water splitting and CO2 reduction, J. Ind. Eng. Chem. 93 (2021) 1-27. https://doi.org/10.1016/j.jiec.2020.09.006

[4] T.O. Ajiboye, O.A. Oyewo, D.C. Onwudiwe, The performance of bismuth-based compounds in photocatalytic applications, J. Surf. Interfac. $23 \quad$ (2021) 10092. https://doi.org/10.1016/j.surfin.2021.100927

[5] A. Ali, W.-C. Oh, Preparation of nanowire like $\mathrm{WSe}_{2}$-graphene nanocomposite for photocatalytic reduction of $\mathrm{CO}_{2}$ into $\mathrm{CH}_{3} \mathrm{OH}$ with the presence of sacrificial agents, Sci. Rep. 7 (2017) 1-11. https://doi.org/10.1038/s41598-017-02075-7

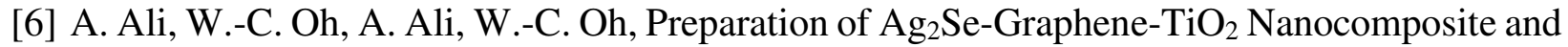
its Photocatalytic Degradation (Rh B), J. Korean Ceram. Soc. 54 (2017) 388-394. https://doi.org/10.4191/kcers.2017.54.5.03

[7] A.A. Ansari, N. Ahmad, M. Alam, S.F. Adil, M.E. Assal, A. Albadri, A.M. Al-Enizi, M. Khan, Optimization of Redox and Catalytic Performance of $\mathrm{LaFeO}_{3}$ Perovskites: Synthesis and Physicochemical Properties, J. Electron. Mater. 48 (2019) 4351-4361. https://doi.org/10.1007/s11664-019-07216-4

[8] L.E. Bell, Cooling, heating, generating power, and recovering waste heat with thermoelectric systems, Science 321 (2008) 1457-1461. http://dx.doi.org/10.1126/science.1158899

[9] I.N. Bhatti, I.N. Bhatti, R.N. Mahato, M. Ahsan, Magnetic behavior, Griffiths phase and magneto-transport study in 3d based nano-crystalline double perovskite $\operatorname{Pr}_{2} \mathrm{CoMnO}_{6}$, Phys. Lett. A 383 (2019) 2326-2332. https://doi.org/10.1016/j.physleta.2019.04.036

[10] R. Borges, R. Thomas, C. Cullinan, J. Coey, R. Suryanarayanan, L. Ben-Dor, L. PinsardGaudart, A. Revcolevschi, Magnetic properties of the double perovskites $\mathrm{A}_{2} \mathrm{FeMoO}_{6} ; \mathrm{A}=\mathrm{Ca}$, Sr, Ba, J. Condens. Matter Phys. 11 (1999) L445. https://doi.org/10.1088/09538984/11/40/104

[11] Y. Cao, X. Gu, H. Yu, W. Zeng, X. Liu, S. Jiang, Y. Li, Degradation of organic dyes by $\mathrm{Si} / \mathrm{SiO}_{\mathrm{x}}$ core-shell nanowires: Spontaneous generation of superoxides without light irradiation, Chemosphere 144 (2016) 836-841. https://doi.org/10.1016/j.chemosphere.2015.09.067

[12] D. Das, R.K. Dutta, A novel method of synthesis of small band gap SnS nanorods and its efficient photocatalytic dye degradation, J. Colloid Interface Sci. 457 (2015) 339-344. https://doi.org/10.1016/j.jcis.2015.07.002

[13] E.A. Dil, M. Ghaedi, A. Ghaedi, A. Asfaram, A. Goudarzi, S. Hajati, M. Soylak, S. Agarwal, V.K. Gupta, Modeling of quaternary dyes adsorption onto $\mathrm{ZnO}-\mathrm{NR}-\mathrm{AC}$ artificial neural network: analysis by derivative spectrophotometry, J. Ind. Eng. Chem. 34 (2016) 186-197. https://doi.org/10.1016/j.jiec.2015.11.010 
[14] S. Feraru, A. Borhan, P. Samoila, C. Mita, S. Cucu-Man, A. Iordan, M. Palamaru, Development of visible-light-driven $\mathrm{Ca}_{2} \mathrm{Fe}_{1-} \mathrm{Sm}_{x} \mathrm{BiO}_{6}$ double perovskites for decomposition of Rhodamine 6G dye, J. Photochem. Photobiol. A 307 (2015) 1-8. https://doi.org/10.1016/j.jphotochem.2015.04.004

[15] M. Ghiasi, A. Malekzadeh, Solar photocatalytic degradation of methyl orange over $\mathrm{La}_{0.7} \mathrm{Sr}_{0.3} \mathrm{MnO}_{3}$ nano-perovskite, Sep. Purif. Technol. $134 \quad$ (2014) 12-19. https://doi.org/10.1016/j.seppur.2014.07.022

[16] P. Hareesh, K. Babitha, S. Shukla, Processing fly ash stabilized hydrogen titanate nano-sheets for industrial dye-removal application, J. Hazard. Mater. 229 (2012) 177-182. https://doi.org/10.1016/j.jhazmat.2012.05.093

[17] F. He, X. Li, K. Zhao, Z. Huang, G. Wei, H. Li, The use of $\mathrm{La}_{1-x} \mathrm{Sr}_{x} \mathrm{FeO}_{3}$ perovskite-type oxides as oxygen carriers in chemical-looping reforming of methane, Fuel 108 (2013) 465473. https://doi.org/10.1016/j.fuel.2012.11.035

[18] N. Kannadasan, N. Shanmugam, S. Cholan, K. Sathishkumar, G. Viruthagiri, R. Poonguzhali, The effect of $\mathrm{Ce}^{4+}$ incorporation on structural, morphological and photocatalytic characters of $\mathrm{ZnO} \quad$ nanoparticles, $\quad$ Mater. $\quad$ Charact. $97 \quad$ (2014) https://doi.org/10.1016/j.matchar.2014.08.021

[19] S. Karimifard, M.R.A. Moghaddam, Application of response surface methodology in physicochemical removal of dyes from wastewater: a critical review, Sci. Total Environ. 640 (2018) 772-797. https://doi.org/10.1016/j.scitotenv.2018.05.355

[20] Z.N. Kayani, S. Riaz, S. Naseem, Magnetic and antibacterial studies of sol-gel dip coated Ce doped $\mathrm{TiO}_{2}$ thin films: Influence of Ce contents, Ceram. Int. 46 (2020) 381-390. https://doi.org/10.1016/j.ceramint.2019.08.272

[21] G. Kiruthigaa, C. Manoharan, M. Bououdina, S. Ramalingam, C. Raju, Structural, optical and photocatalytic properties of Ce-doped $\mathrm{SnS}_{2}$ nanoflakes, Solid State Sci. 44 (2015) 32-38. https://doi.org/10.1016/j.solidstatesciences.2015.04.003

[22] K.-I. Kobayashi, T. Kimura, H. Sawada, K. Terakura, Y. Tokura, Room-temperature magnetoresistance in an oxide material with an ordered double-perovskite structure, Nature 395 (1998) 677-680. https://doi.org/10.1038/27167

[23] A. Konsowa, M. Ossman, Y. Chen, J.C. Crittenden, Decolorization of industrial wastewater by ozonation followed by adsorption on activated carbon, J. Hazard. Mater. 176 (2010) 181185. https://doi.org/10.1016/j.jhazmat.2009.11.010

[24] P. Kumar, S. Presto, A. Sinha, S. Varma, M. Viviani, P. Singh, Effect of samarium $\left(\mathrm{Sm}^{3+}\right)$ doping on structure and electrical conductivity of double perovskite $\mathrm{Sr}_{2} \mathrm{NiMoO}_{6}$ as anode material for SOFC, J. Alloys Compd. 725 (2017) 1123-1129. https://doi.org/10.1016/j.jallcom.2017.07.211

[25] S. Kumar, W. Ahlawat, G. Bhanjana, S. Heydarifard, M.M. Nazhad, N. Dilbaghi, Nanotechnology-based water treatment strategies, J. Nanosci. Nanotechnol. 14 (2014) 18381858. https://doi.org/10.1166/jnn.2014.9050

[26] S. Kumar, W. Ahlawat, R. Kumar, N. Dilbaghi, Graphene, carbon nanotubes, zinc oxide and gold as elite nanomaterials for fabrication of biosensors for healthcare, Biosens. Bioelectron. 70 (2015) 498-503. https://doi.org/10.1016/j.bios.2015.03.062

[27] F. Li, X. Li, S. Ma, L. Chen, W. Li, C. Zhu, X. Xu, Y. Chen, Y. Li, G. Lawson, Influence of $\mathrm{Ce}$ doping on microstructure of $\mathrm{ZnO}$ nanoparticles and their acetone sensing properties, J. Alloys Compd. 649 (2015) 1136-1144. https://doi.org/10.1016/j.jallcom.2015.07.251 
[28] H. Li, F. Li, Z. Shen, S.-T. Han, J. Chen, C. Dong, C. Chen, Y. Zhou, M. Wang, Photoferroelectric perovskite solar cells: Principles, advances and insights, Nano Today 37 (2021) 101062. https://doi.org/10.1016/j.nantod.2020.101062

[29] C. López, M. Viola, J.C. Pedregosa, R.E. Carbonio, R.D. Sánchez, M. Fernández-Díaz, $\mathrm{La}^{3+}$ doping of the $\mathrm{Sr}_{2} \mathrm{CoWO}_{6}$ double perovskite: A structural and magnetic study, J. Solid State Chem. 181 (2008) 3095-3102. https://doi.org/10.1016/j.jssc.2008.08.007

[30] J. Luan, M. Li, K. Ma, Y. Li, Z. Zou, Photocatalytic activity of novel $\mathrm{Y}_{2} \mathrm{InSbO}_{7}$ and $\mathrm{Y}_{2} \mathrm{GdSbO}_{7}$ nanocatalysts for degradation of environmental pollutant rhodamine $\mathrm{B}$ under visible light irradiation, Chem. Eng. J. $167 \quad$ (2011) 162-171. https://doi.org/10.1016/j.cej.2010.12.015

[31] A. Maignan, B. Raveau, C. Martin, M. Hervieu, Large intragrain magnetoresistance above room temperature in the double perovskite $\mathrm{Ba}_{2} \mathrm{FeMoO}_{6}$, J. Solid State Chem. 144 (1999) 224227. https://doi.org/10.1006/jssc.1998.8129

[32] N. Miniajluk, R. Boulesteix, P.J. Dereń, Spark Plasma Sintering of double perovskite $\mathrm{Ba}_{2} \mathrm{MgWO}_{6}$ doped with $\mathrm{Ce}^{3+}$ : Part I-Structural and microstructural characterizations, Ceram. Int. 46 (2020) 7602-7608. https://doi.org/10.1016/j.ceramint.2019.11.260

[33] A. Mittal, J. Mittal, A. Malviya, V. Gupta, Removal and recovery of Chrysoidine Y from aqueous solutions by waste materials, J. Colloid Interface Sci. 344 (2010) 497-507. https://doi.org/10.1016/j.jcis.2010.01.007

[34] N. Moreno, L. Barbosa, D.R. Ardila, J.P. Andreeta, Magnetic Measurements on Single Crystal of Double Perovskite $\mathrm{Ca}_{2} \mathrm{FeMoO}_{6}$, J. Supercond. Nov. Magn. 26 (2013) 2501-2503. https://doi.org/10.1007/s10948-012-1723-x

[35] K. Peng, L. Fu, H. Yang, J. Ouyang, Perovskite LaFeO 3/montmorillonite nanocomposites: synthesis, interface characteristics and enhanced photocatalytic activity, Sci. Rep. 6 (2016) 110. https://doi.org/10.1038/srep19723

[36] M. Ponnar, C. Thangamani, P. Monisha, S. Gomathi, K. Pushpanathan, Influence of Ce doping on $\mathrm{CuO}$ nanoparticles synthesized by microwave irradiation method, Appl. Surf. Sci. 449 (2018) 132-143. https://doi.org/10.1016/j.apsusc.2018.01.126

[37] S. Porhemmat, A. Rezvani, M. Ghaedi, A. Asfaram, A. Goudarzi, Ultrasonic treatment of wastewater contaminated with various dyes using tin oxide hydroxide nanoparticles loaded on activated carbon: Synthesis, performance, mechanism and statistical optimization, Appl. Organomet. Chem. 31 (2017) e3860. https://doi.org/10.1002/aoc.3860

[38] M. Rauf, S.S. Ashraf, Fundamental principles and application of heterogeneous photocatalytic degradation of dyes in solution, Chem. Eng. Technol. 151 (2009) 10-18. https://doi.org/10.1016/j.cej.2009.02.026

[39] S. Ravi, Spin transport through silicon using a double perovskite-based magnetic tunnel $\begin{array}{lllll}\text { junction, } & \text { Superlattices } & \text { Microstruct. } & 147 & \text { (2020) }\end{array}$ https://doi.org/10.1016/j.spmi.2020.106688

[40] M. Retuerto, M. Martinez-Lope, M. Garcia-Hernandez, J. Alonso, High-pressure synthesis of the double perovskite $\mathrm{Sr}_{2} \mathrm{FeMoO}_{6}$ : increment of the cationic ordering and enhanced magnetic properties, J. Condens. Matter Phys. 21 (2009) 186003. https://doi.org/10.1088/09538984/21/18/186003

[41] P. Roy, I. Bose, T. Maiti, Synthesis and characterization of $\operatorname{Sr}_{2} \mathrm{TiMO}_{6}(\mathrm{M}=\mathrm{Fe}, \mathrm{Co})$ double perovskites for high temperature thermoelectric applications, Integr. Ferroelectr. 174 (2016) 34-42. https://doi.org/10.1080/10584587.2016.1190253 
[42] S. Rtimi, C. Pulgarin, R. Sanjines, J. Kiwi, Kinetics and mechanism for transparent polyethylene- $\mathrm{TiO}_{2}$ films mediated self-cleaning leading to $\mathrm{MB}$ dye discoloration under sunlight irradiation, Appl. Catal. B. $162 \quad$ (2015) 236-244. https://doi.org/10.1016/j.apcatb.2014.05.039

[43] H. Sabeeh, S. Musaddiq, M. Shahid, M.A. Khan, M. Sher, M.F. Warsi, Rare earth substituted nanocrystalline $\mathrm{LaFeO}_{3}$ perovskites and their composites with reduced graphene oxide for enhanced photocatalytic and other potential applications, Mater. Res. Express 5 (2018) 065062. https://doi.org/10.1088/2053-1591/aacd1d

[44] J. Saini, V. Garg, R. Gupta, Removal of methylene blue from aqueous solution by $\mathrm{Fe}_{3} \mathrm{O}_{4} @$ $\mathrm{Ag} / \mathrm{SiO}_{2}$ nanospheres: synthesis, characterization and adsorption performance, J. Mol. Liq. 250 (2018) 413-422. https://doi.org/10.1016/j.molliq.2017.11.180

[45] Y. Sha, I. Mathew, Q. Cui, M. Clay, F. Gao, X.J. Zhang, Z. Gu, Rapid degradation of azo dye methyl orange using hollow cobalt nanoparticles, Chemosphere 144 (2016) 1530-1535.

[46] Y.M. Slokar, A.M. Le Marechal, Methods of decoloration of textile wastewaters, Dyes Pigm. 37 (1998) 335-356. https://doi.org/10.1016/j.chemosphere.2015.10.040

[47] Y.-F. Sun, Y.-Q. Zhang, B. Hua, Y. Behnamian, J. Li, S.-H. Cui, J.-H. Li, J.-L. Luo, Molybdenum doped $\mathrm{Pr}_{0.5} \mathrm{Ba}_{0.5} \mathrm{MnO}_{3-\delta}$ (Mo-PBMO) double perovskite as a potential solid oxide fuel cell anode material, J. Power Sources 301 (2016) 237-241. https://doi.org/10.1016/j.jpowsour.2015.09.127

[48] B. Ullah, W. Lei, X.-Q. Song, X.-H. Wang, W.-Z. Lu, Crystal structure, defect chemistry and radio frequency relaxor characteristics of Ce-Doped $\mathrm{SrTiO}_{3}$ perovskite, J. Alloys Compd. 728 (2017) 623-630. https://doi.org/10.1016/j.jallcom.2017.08.292

[49] B. Wang, F.C. de Godoi, S. Zheng, I.R. Gentle, C. Li, Enhanced photocatalytic properties of reusable $\mathrm{TiO}_{2}$-loaded natural porous minerals in dye wastewater purification, Powder Technol. 302 (2016) 426-433. https://doi.org/10.1016/j.powtec.2016.09.003

[50] G.W. Ward, The Grove encyclopedia of materials and techniques in art, Grove Encyclopedia, 2008. https://doi.org/10.5860/choice.46-5940

[51] S. Won, S. Choi, B. Chung, D. Park, J. Park, Y.-S. Yun, Biosorptive decolorization of Reactive Orange 16 using the waste biomass of Corynebacterium glutamicum, Ind. Eng. Chem. Res. 43 (2004) 7865-7869. https://doi.org/10.1021/ie049559o

[52] A.L. Al-Otaibi, T. Ghrib, M. Alqahtani, M.A. Alharbi, R. Hamdi, I. Massoudi, Structural, optical and photocatalytic studies of Zn doped MoO3 nanobelts, Chemical Physics 525 (2019) 110410. https://doi.org/10.1016/j.chemphys.2019.110410

[53] Y. Xu, R.E. Lebrun, P.-J. Gallo, P. Blond, Treatment of textile dye plant effluent by nanofiltration membrane, Sep. Sci. Technol. 34 (1999) 2501-2519. https://doi.org/10.1081/SS100100787

[54] L. Zeng, T. Peng, H. Sun, J. Yang, Y. Li, Y. Qin, Fe-doped $\mathrm{LaNi}_{1-\mathrm{x}} \mathrm{FexO}_{3}$ perovskite oxides for enhanced visible-light-driven photocatalytic activity, J. Solid State Chem. 297 (2021) 122033. https://doi.org/10.1016/j.jssc.2021.122033

[55] G. Zhang, G. Li, F. Liao, Y. Fu, M. Xiong, J. Lin, Crystal growth and magnetic properties of the double perovskites $\mathrm{R}_{2} \mathrm{MnNiO}_{6}(\mathrm{R}=\mathrm{Pr}, \mathrm{Sm}$ and $\mathrm{Ho})$ by a hydrothermal route, J. Cryst. Growth 327 (2011) 262-266. https://doi.org/10.1016/j.jcrysgro.2011.06.002

[56] J. Zhang, Z. Zhang, Y. Chen, X. Xu, C. Zhou, G. Yang, W. Zhou, Z. Shao, Materials design for ceramic oxygen permeation membranes: Single perovskite vs. single/double perovskite composite, a case study of tungsten-doped barium strontium cobalt ferrite, J. Membr. Sci. 566 (2018) 278-287. https://doi.org/10.1016/j.memsci.2018.09.004 
Figures

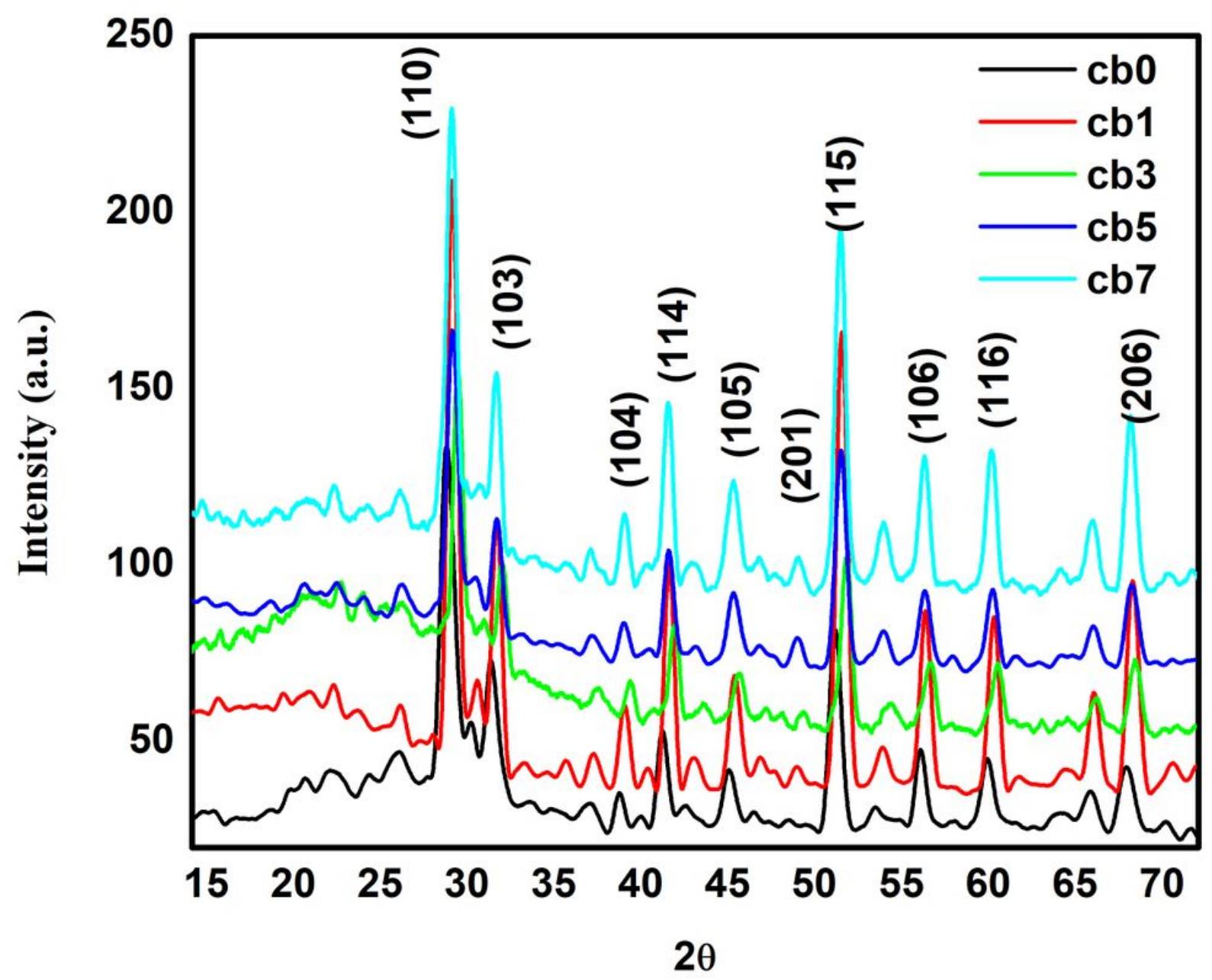

Figure 1

X-ray diffraction patterns for pure and Ce-doped Ba2TiMoO6 

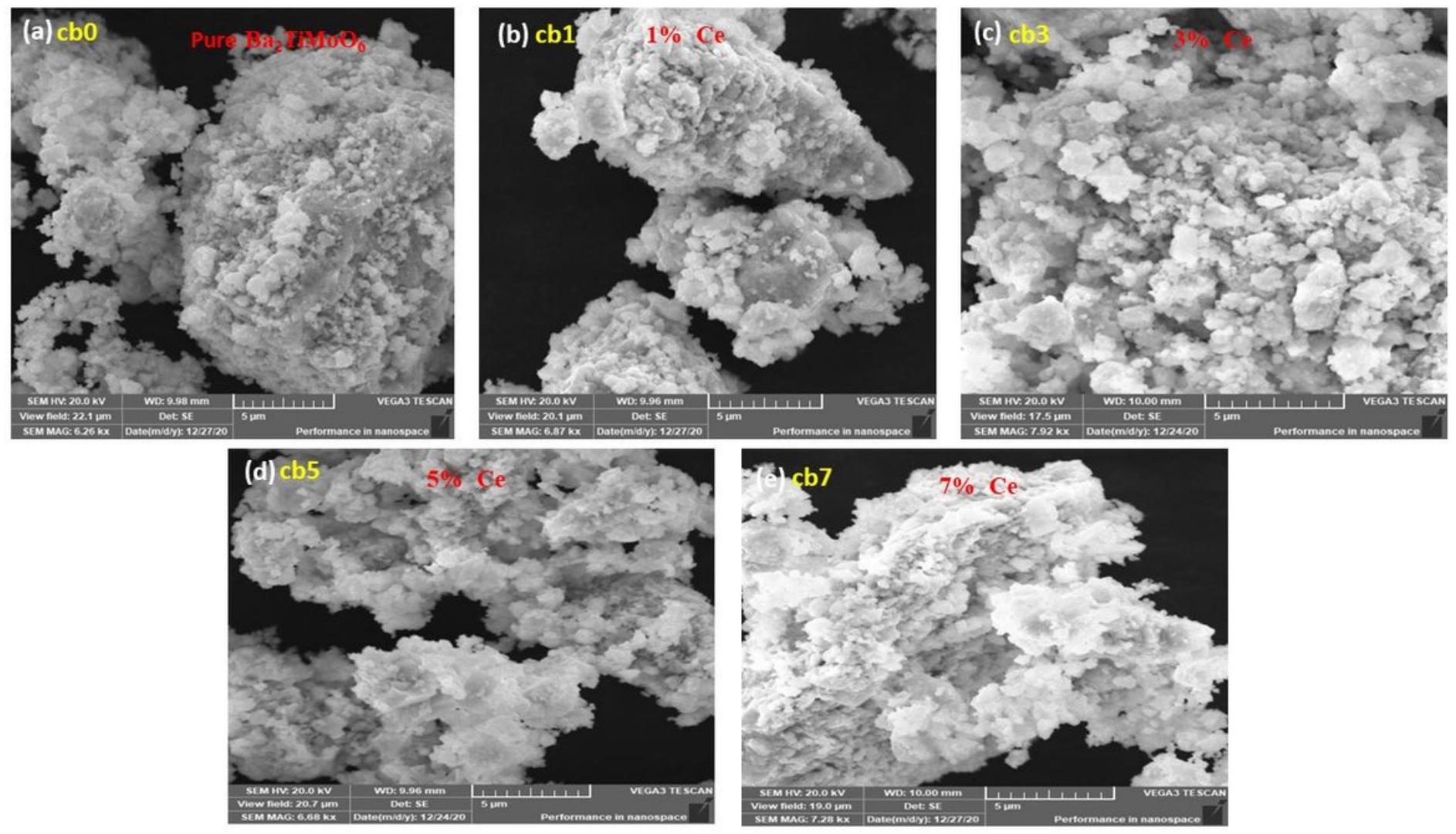

Figure 2

SEM images of (a) pure Ba2TiMoO6 (b) 1 wt $\%$ (c) $3 w t \%$ (d) 5 wt $\%$ (e) $7 w t \%$ Ce-doped Ba2TiMoO6 NPs
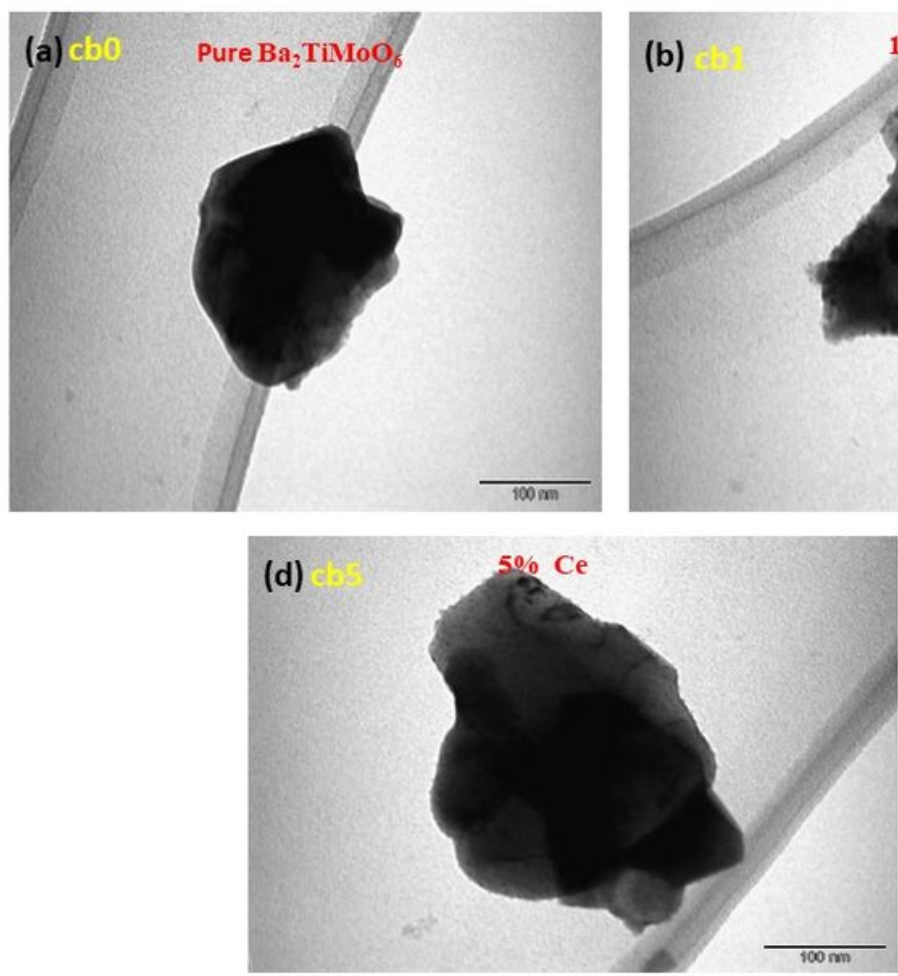
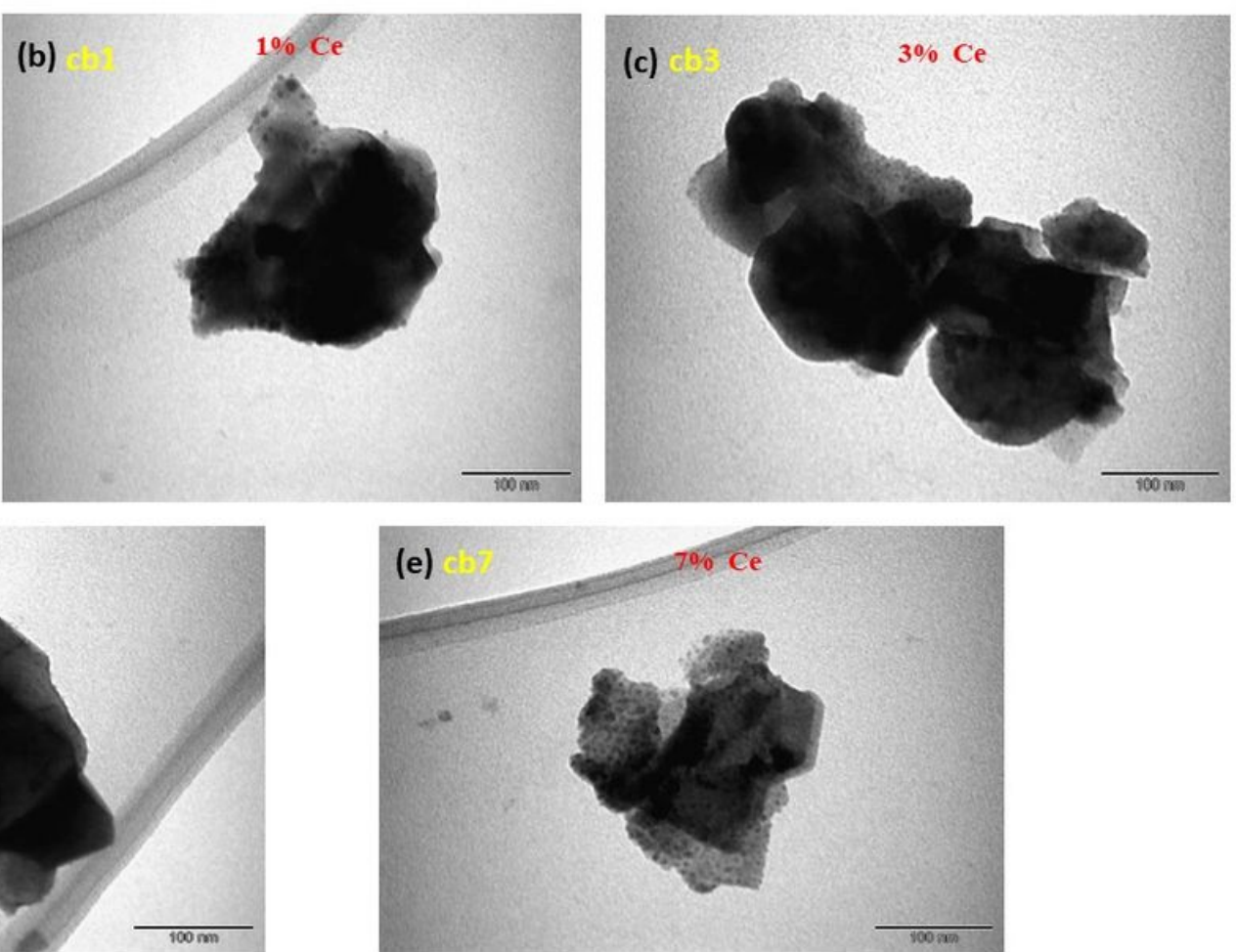
Figure 3

TEM images of (a) Pure Ba2TiMoO6 (b) 1 wt\% (c) 3 wt\% (d) 5 wt\% (e) 7 wt $\%$ Ce-doped Ba2TiMoO6 NPs

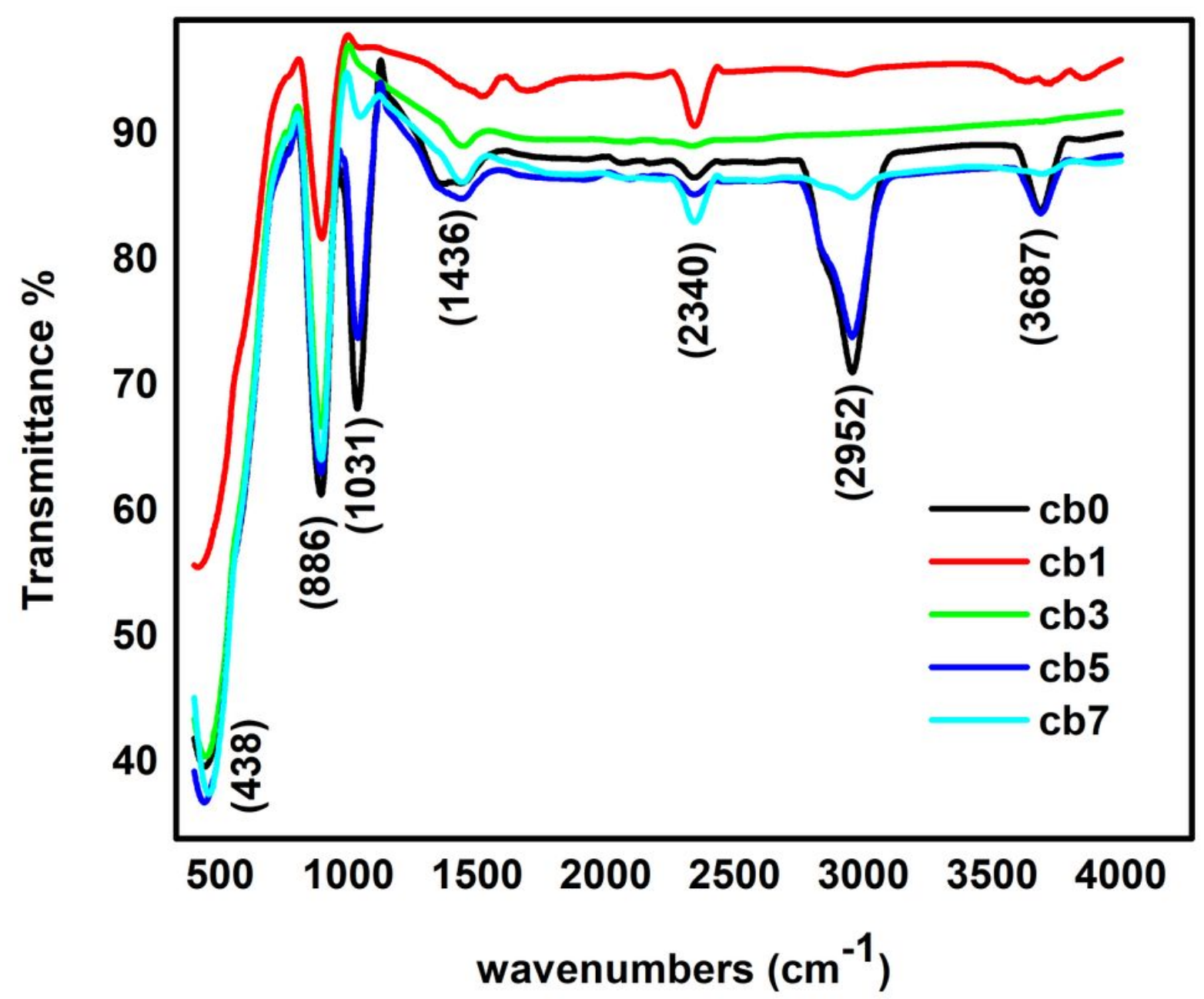

Figure 4

The FTIR spectra of pure and Ce doped Ba2TiMoO6 samples (range 4000-400 cm-1). 


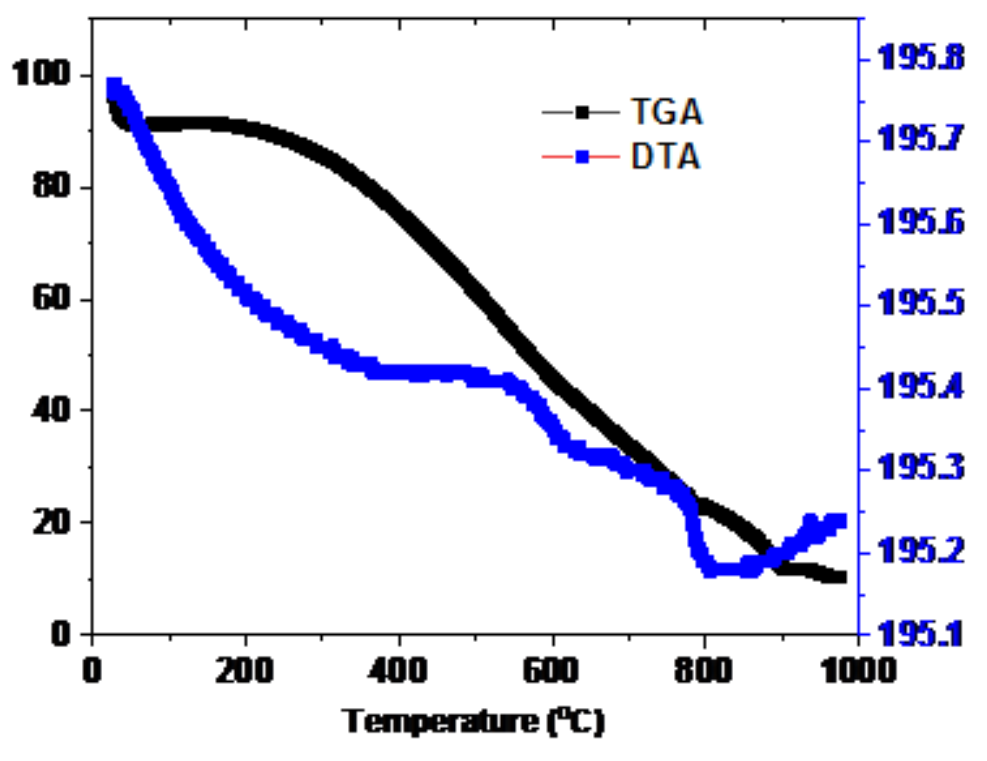

Figure 5

TGA and DTA of the pure Ba2TiMoO6 double perovskite. 

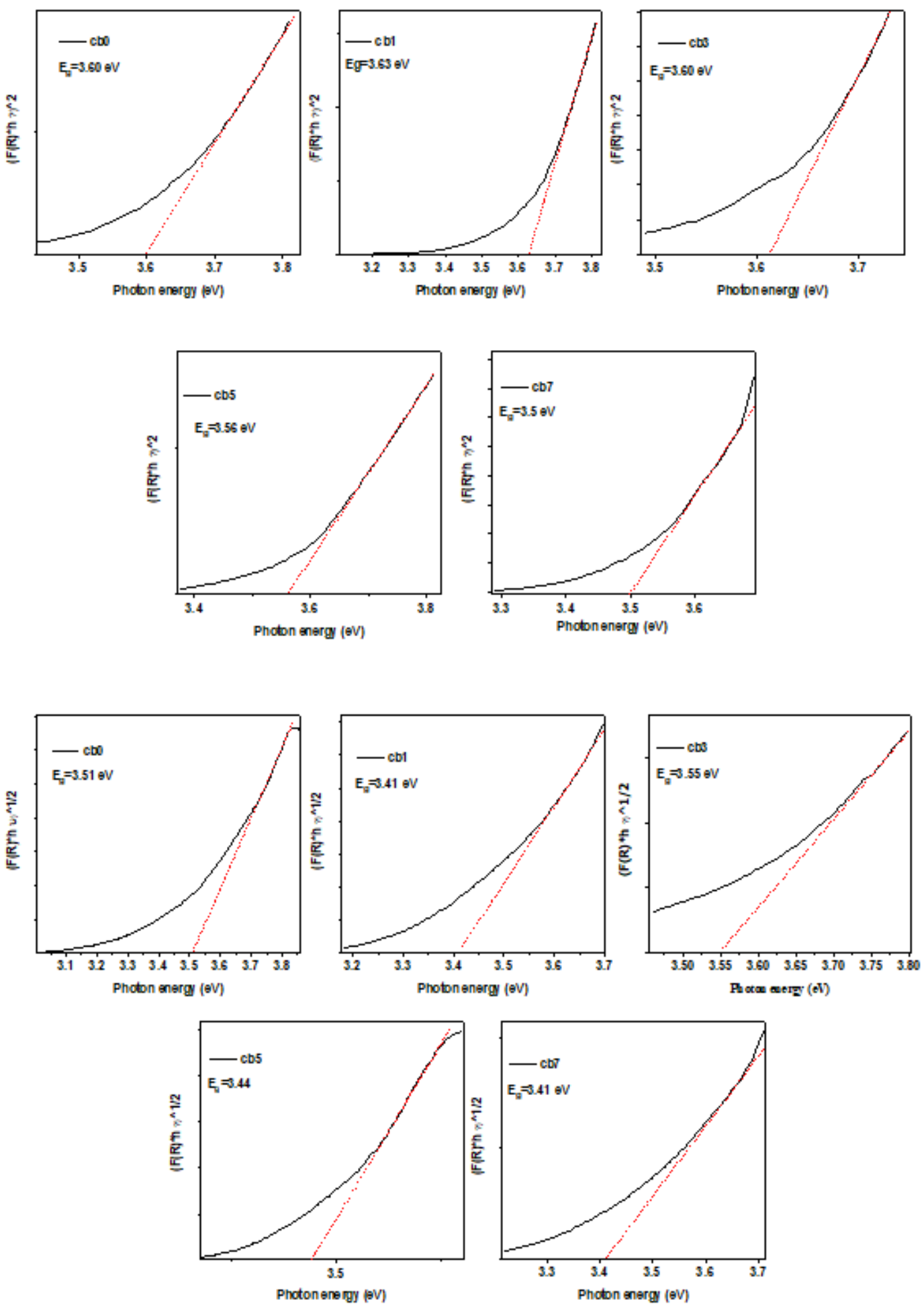

\section{Figure 6}

(a). Kubelka-Munk plots and direct-band gap values of the Pure Ba2TiMoO6, 1\%, 3\%, 5\% and 7\% Cedoped Ba2TiMoO6. (b). Kubelka-Munk plots and indirect-band gap values of the Pure Ba2TiMoO6, 1\% , $3 \%, 5 \%$ and $7 \%$ Ce-doped Ba2TiMoO6. 


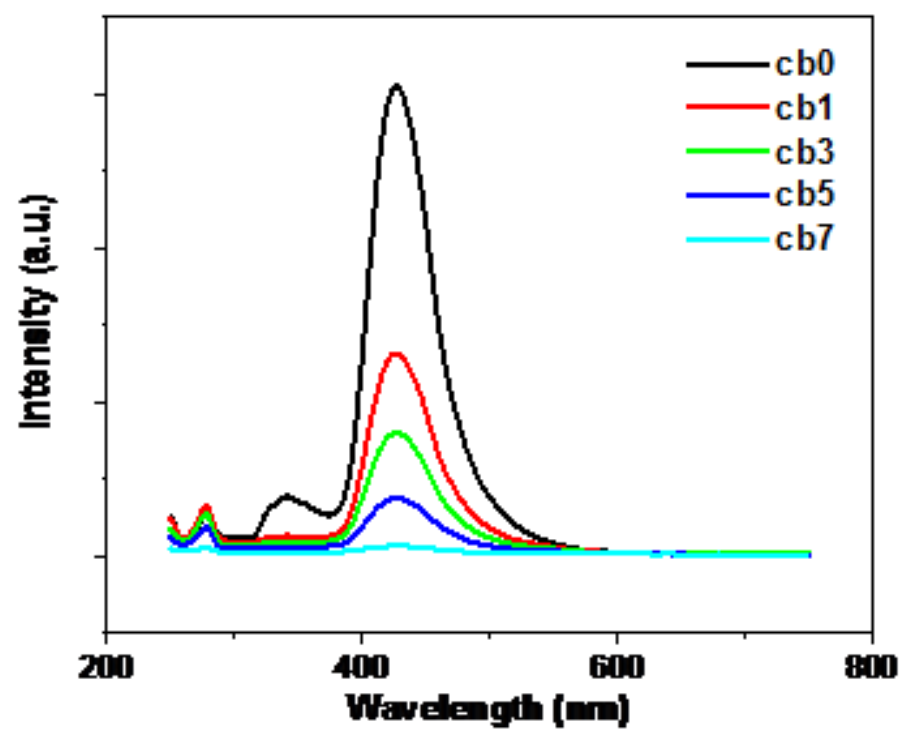

Figure 7

Photoluminescence spectra of pure and Ce doped Ba2TiMoO6
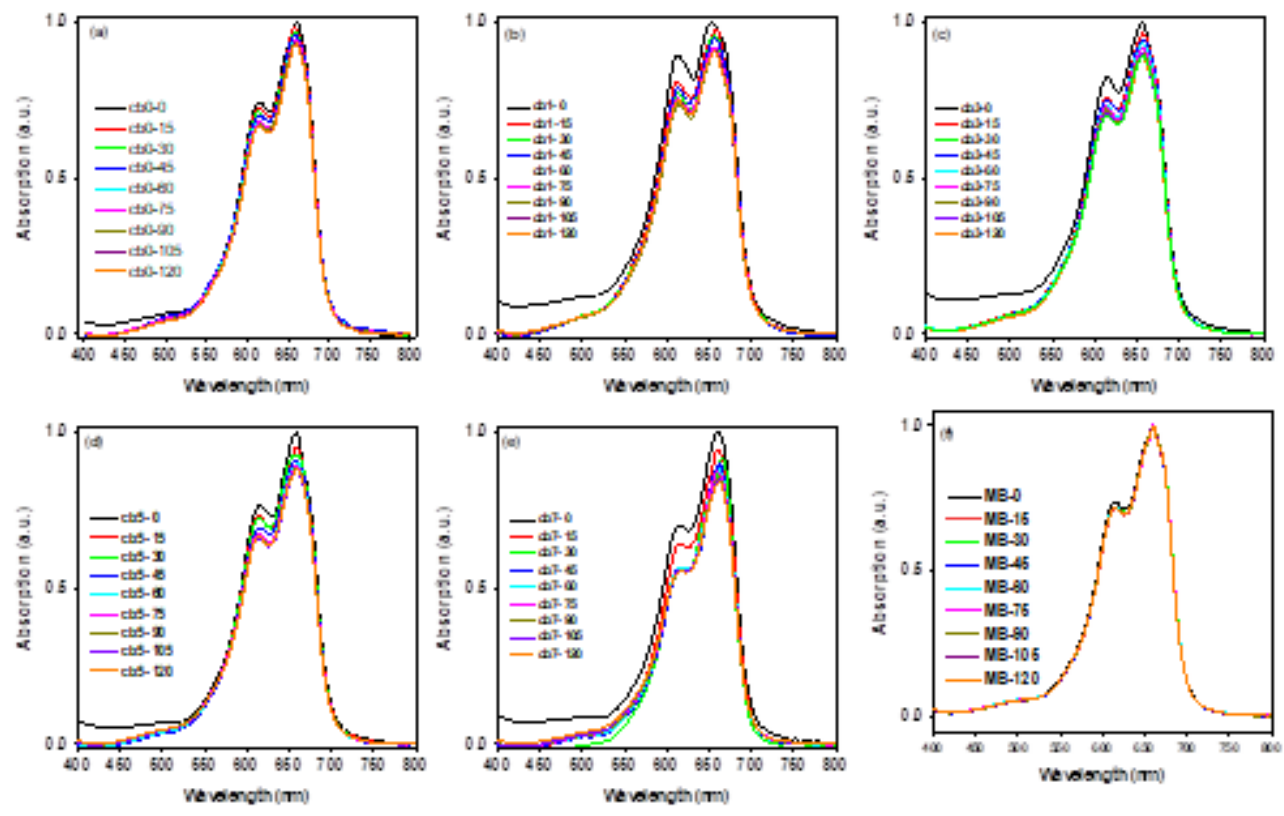

Figure 8

Degradation spectra of MB with Ba2TiMoO6 catalysts for different Ce concentrations (a-e) and without any catalyst (f). 


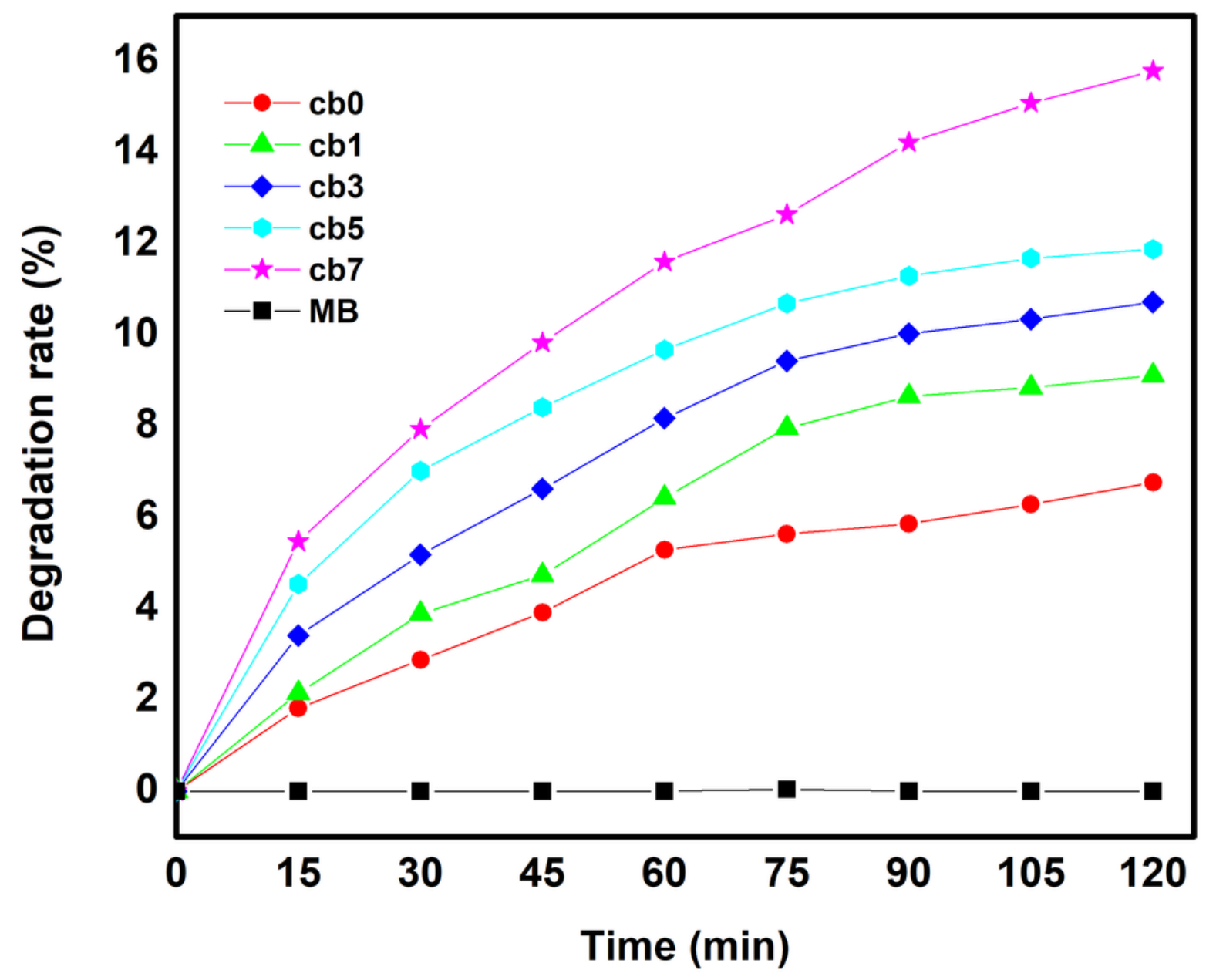

Figure 9

Degradation rate of the prepared samples versus time with different Ce doping percentages

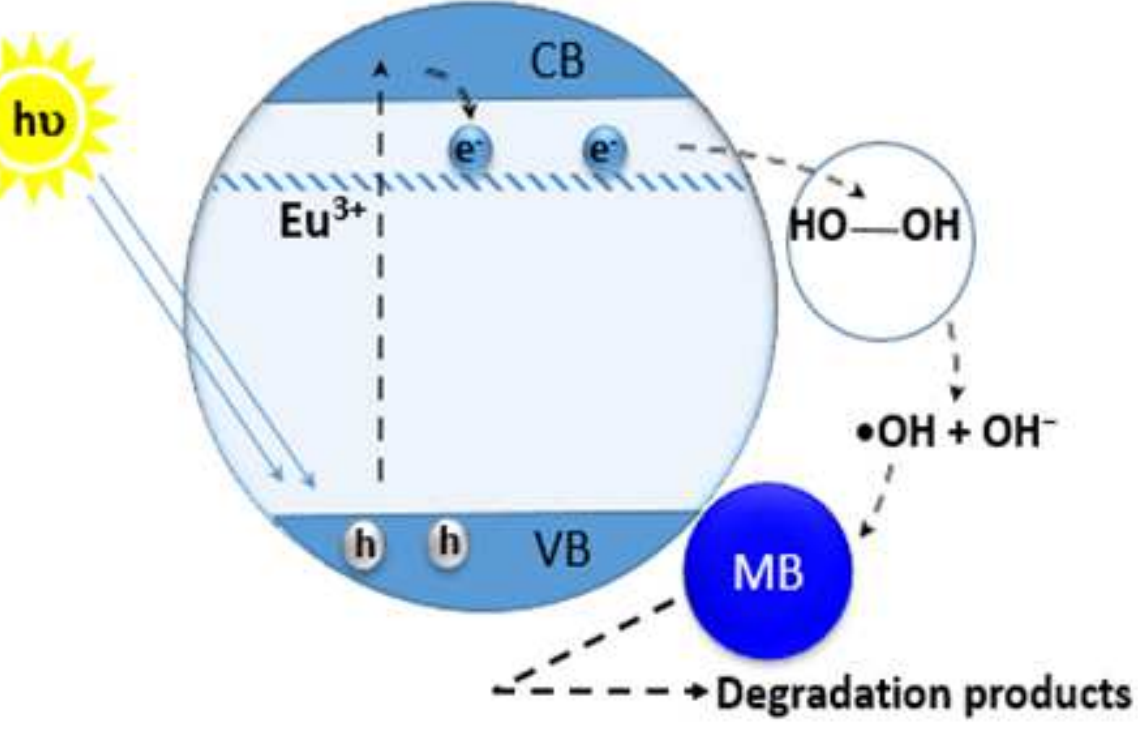


Figure 10

Photocatalytic mechanism for the degradation of MB by Ce-doped Ba2TiMoO6 